\title{
AUTOLOGOUS CARTILAGE FRAGMENTS IN A COMPOSITE SCAFFOLD FOR ONE STAGE OSTEOCHONDRAL REPAIR IN A GOAT MODEL
}

\author{
Antonio Marmotti ${ }^{1 *}$, Matteo Bruzzone ${ }^{1}$, Davide E Bonasia ${ }^{1}$, Filippo Castoldi ${ }^{1}$, Mitzy Mauthe Von Degerfeld ${ }^{2}$, \\ Cristina Bignardi ${ }^{4}$, Silvia Mattia $^{3}$, Alessio Maiello $^{1}$, Roberto Rossi ${ }^{1}$ and Giuseppe M Peretti ${ }^{5}$ \\ ${ }^{1}$ University of Torino, Mauriziano Hospital, Department of Orthopaedics and Traumatology, Torino, Italy \\ ${ }^{2}$ University of Torino, Department of Animal Pathology, Surgery Section, Turin, Italy \\ ${ }^{3}$ University of Torino, Molecular Biotechnology Center, Turin, Italy \\ ${ }^{4}$ Polytechnic of Torino, Department of Mechanics, Turin, Italy. \\ ${ }^{5}$ Department of Biomedical Sciences for Health, University of Milan, Milan, Italy, and IRCCS Istituto Ortopedico \\ Galeazzi, Milan, Italy
}

\begin{abstract}
We propose a culture-free approach to osteochondral repair with minced autologous cartilage fragments loaded onto a scaffold composed of a hyaluronic acid (HA)-derived membrane, platelet-rich fibrin matrix (PRFM) and fibrin glue. The aim of the study was to demonstrate in vitro the outgrowth of chondrocytes from cartilage fragments onto this scaffold and, in vivo, the formation of functional repair tissue in goat osteochondral defects. Two sections were considered: 1) in vitro: minced articular cartilage from goat stifle joints was loaded onto scaffolds, cultured for 1 or 2 months, and then evaluated histologically and immunohistochemically; 2) in vivo: 2 unilateral criticallysized trochlear osteochondral defects were created in 15 adult goats; defects were treated with cartilage fragments embedded in the scaffold (Group 1), with the scaffold alone (Group 2), or untreated (Group 3). Repair processes were evaluated morphologically, histologically, immunohistochemically and biomechanically at 1, 3, 6 and 12 months. We found that in vitro, chondrocytes from cartilage fragments migrated to the scaffold and, at 2 months, matrix positive for collagen type II was observed in the constructs. In vivo, morphological and histological assessment demonstrated that cartilage fragment-loaded scaffolds led to the formation of functional hyaline-like repair tissue. Repair in Group 1 was superior to that of control groups, both histologically and mechanically. Autologous cartilage fragments loaded onto an HA/ PRFM/fibrin glue scaffold provided a viable cell source and allowed for an improvement of the repair process of osteochondral defects in a goat model, representing an effective alternative for one-stage repair of osteochondral lesions.
\end{abstract}

Keywords: One-stage cartilage repair; cartilage fragments; hyaluronic acid-derived membrane; fibrin glue; plateletrich fibrin matrix; scaffold; goat model; chondrocytes; osteochondral defects; nanoindentation.

*Address for correspondence:

Antonio Marmotti

Department of Orthopaedics and Traumatology

University of Torino Medical School

Mauriziano "Umberto I" Hospital

Largo Turati 62

10128 Torino, Italy
Telephone Number: +39-3388308700

FAX Number: +39-0115082050

E-mail: antonio.marmotti@inwind.it

\section{Introduction}

Cartilage injuries are commonly found in orthopaedic surgery, and spontaneous healing of osteochondral lesions leads to the formation of fibrocartilage, a type of functional repair tissue that has different biochemical composition and inferior biomechanical properties from those of hyaline articular cartilage. Thus, finding a viable cell source and a suitable scaffold are significant milestones for cartilage repair, and the presence of chondrogenic cells in cartilage defects seems to be a key feature for good clinical and histological results. The most commonly available treatments to enhance the quality of repair of symptomatic deep cartilage and osteochondral lesions include: 1) bone marrow stimulation (microfractures, MF) (Mithoefer et al., 2005); 2) osteochondral autograft transplantation (OAT) (Bobic, 1999) (Gudas et al., 2012); and 3) autologous chondrocyte implantation (ACI) (Peterson et al., 2010). MF and single-plug OAT are usually implemented for small chondral and osteochondral defects $\left(<1-2 \mathrm{~cm}^{2}\right)$, while for larger lesions, multiple OAT and ACI are both preferable treatment options (Bekkers et al., 2009; De Windt et al., 2012).

Bone marrow stimulation through microfractures is the simplest and most economic one-step approach, but often results in the generation of mixed fibrocartilage tissue that tends to degenerate over time (Hunziker, 1999a; Shapiro et al., 1993). Osteochondral autograft transplantation facilitates the formation of more homologous tissue at the lesion site, but raises concerns about donor-site morbidity, technical difficulties, and integration of the graft at the interface with the receiving site. Indeed, with OAT, mature hyaline cartilage is transferred from an area that bears less weight to the defect site, but the technical difficulties to obtain a careful restoration of the curvature of the articular surface are limiting factors. Moreover, in larger defects, multiple plugs are needed, and close contact with the surrounding host bone could be incomplete, compromising plug integration. Osteochondral allografts could overcome some of these limitation, but fresh graft availability and high costs are still limiting factors of this procedure (Gomoll et al., 2010). Autologous chondrocyte 

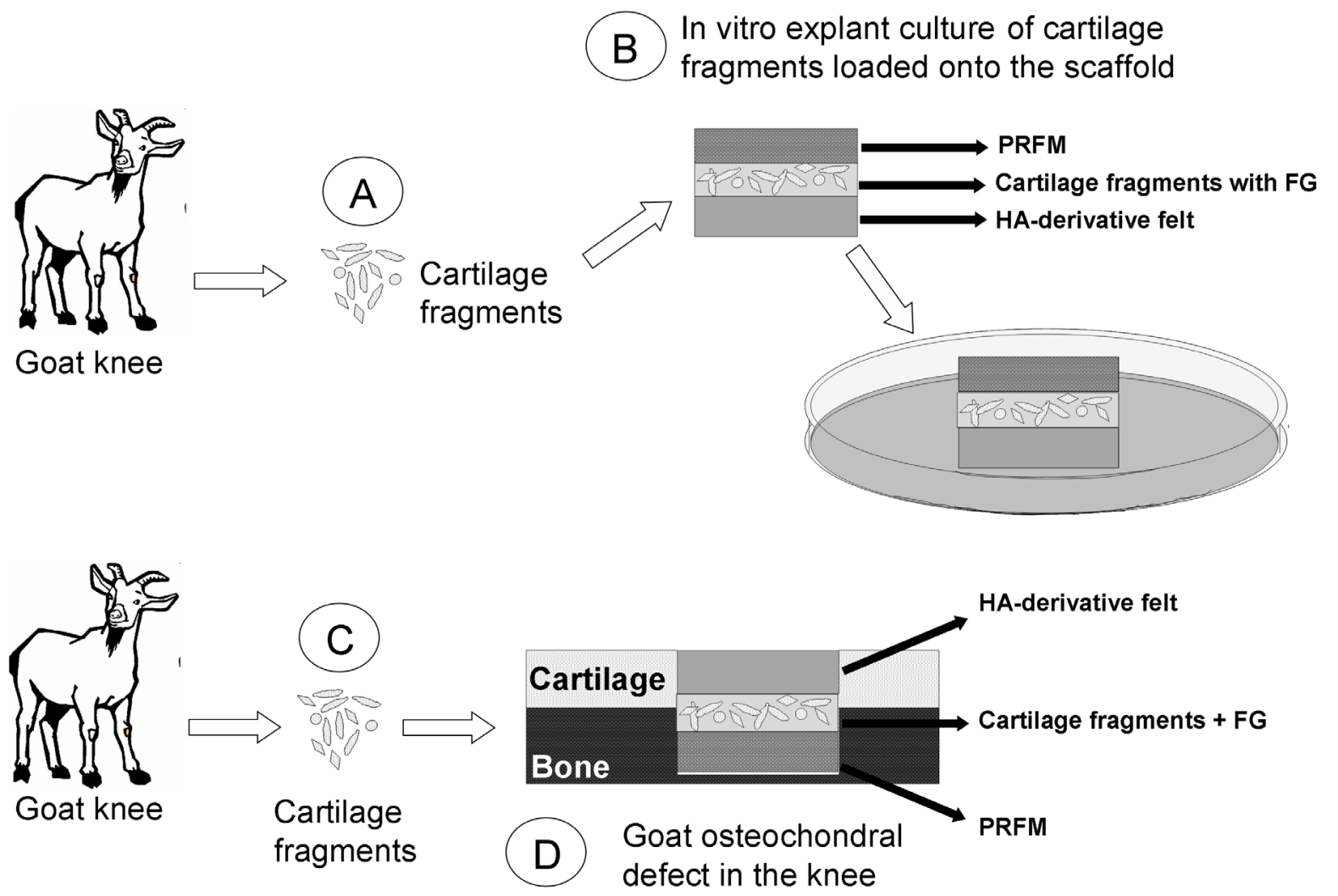

Fig. 1. Study design. In vitro study: cartilage fragments were harvested from goat knees (A); minced cartilage fragments were loaded onto the scaffold (B); In vivo study: cartilage fragments were harvested from goat knees (C), minced, loaded onto the scaffold (D) and used as a cell source for the repair of osteochondral defects in goat knees (study group A). FG, fibrin glue; HA, hyaluronic acid; PRFM, platelet-rich fibrin matrix.

implantation leads to a hyaline-like regenerative tissue with better histological and clinical results than microfractures as well as durable properties. It can be used both with a chondrocyte suspension or with a 3-D pre-loaded membrane (MACI, Hyalograft $\mathrm{C}$ and others), and combined procedures are being exploited for deeper defects, involving transplantation of trabecular bone in association with cell transplantation (Bartlett et al., 2005). However, there are still several limitations to autologous chondrocyte implantation, as multiple surgical procedures are required and costly chondrocyte culture is needed in order to expand cells in vitro before implantation.

Recently, tissue engineering is developing new alternatives to overcome these limitations and new onestage methods have been investigated in order to obtain controlled differentiation of repair tissue with good functional properties and valuable histological features, avoiding cell manipulation, multiple surgical procedures, high costs and major patient morbidity. The autologous matrix-induced chondrogenesis (AMIC) technique is a one-step procedure for focal chondral and osteochondral defects, combining subchondral microfractures with a collagen I/III membrane secured with fibrin glue or sutures. This enables bone marrow cell adhesion, optimising fibrocartilaginous repair (Benthien and Behrens, 2011); platelet-rich plasma gel can also be combined to enhance repair processes (Dhollander et al., 2010). Maioregen
(Fin-Ceramica Faenza S.p.A., Faenza-Italy) is a thick, nanostructured biomimetic collagen and hydroxyapatite scaffold used for treatment of large osteochondral lesions. As in the AMIC technique, cell migration from the surrounding host bone and bone marrow is required in order to colonise the scaffold and achieve functional repair (Kon et al., 2010a; 2010b). Osteochondral morselised grafts have been proposed as a "paste" without any scaffold for one-stage repair of full thickness articular cartilage lesions and osteochondral defects, both in animal and human studies (Stone et al., 2006; Mahadev et al., 2001). This solution implies an undifferentiated mixed cell source from cartilage, bone and blood for the repair process (Stone et al., 2006). Bone marrow concentrate and platelet gel have also been recently combined with a hyaluronic acid membrane for one-step repair of osteochondral lesions of knees and ankles (Buda et al., 2010; Giannini et al., 2009). Results and effectiveness of all these procedures are promising, but still under investigation.

To preserve the advantages of chondrocyte therapy, whilst at the same time reducing cell manipulation, cartilage fragments have been also investigated in animal models as well as a human trial, as being a suitable cell source for one-step cartilage repair - in association with collagen membranes or polydioxanone mesh (cartilage autograft implantation system, CAIS) (Cole et al., 2011; Frisbie et al., 2009; Lu et al., 2006). The rationale of this 
repair technique is the spontaneous ability of chondrocytes to migrate from the cartilage chips and proliferate into the scaffold. Cartilage fragmentation greatly increases tissue surface area and maximises the number of cells that can then interact with the three-dimensional structure of the scaffold. Fragmentation also separates cell-matrix bonding and promotes a "motile phenotype", eliciting cell outgrowth toward the surrounding environment (Reindel et al., 1995).

This study proposes a one-stage culture-free chondrocyte approach to osteochondral repair, using autologous cartilage fragments as a cell source, loaded onto an absorbable scaffold composed of a hyaluronic acid-derived membrane (Hyaff-11), autologous plateletrich fibrin matrix (PRFM, Cascade system) and injectable fibrin glue. Based on the results from previous investigators on the chondrogenic potential of fresh minced cartilage chips (Cole et al., 2011; Frisbie et al., 2009; Lu et al., 2006), the present study aims to investigate (Fig. 1): (a) in vitro - the outgrowth of chondrocytes derived from chondral fragments, obtained by mechanical fragmentation of articular cartilage, loaded onto the aforementioned absorbable scaffold; and (b) in vivo - the repair efficacy of the experimental composite in goat trochlear lesions, a clinically relevant large animal model. For this purpose, deep osteochondral defects were treated with autologous cartilage fragments loaded onto the absorbable scaffold; other defects were either treated with the scaffold alone or left untreated for control groups.

\section{Materials and Methods}

Approvals were obtained both from the Ethical Committee of the MBC (Molecular Biotechnology Centre), University of Torino, and from the Animal Care and Use Centre (CISRA), Faculty of Veterinary Medicine, University of Torino.

\section{Method for platelet-rich fibrin matrix (PRFM ) preparation}

A goat blood sample was collected preoperatively $(10 \mathrm{~mL})$ in order to obtain autologous PRFM (Cascade ${ }^{\circledR}$ Autologous Platelet System, MTF Sports Medicine, Cascade Medical Enterprises, Wayne, NJ, USA) (Hall et al., 2009; Castillo et al., 2011). Briefly, according to the manufacturer's instructions, $10 \mathrm{~mL}$ of peripheral goat blood were collected in a supplied sterile blood collection/separation tube (Tube 1). Mean concentration of original platelets was $348 \mathrm{x}$ $10^{3}$ platelets $/ \mu \mathrm{L}$ (range 166-504). Tube 1 was centrifuged at $1100 \mathrm{~g}$ for $6 \mathrm{~min}$ to obtain platelet rich plasma (PRP). Following centrifugation, the supernatant on top of the separation gel was composed of PRP, whereas red and white blood cell fractions were located below the gel. PRP supernatants were transferred to a second tube (Tube $2)$, containing a calcium chloride additive $(0.25 \mathrm{~mL} 1 \mathrm{M}$ $\mathrm{CaCl}_{2}$ ). Tube 2 was centrifuged for $15 \mathrm{~min}$ at $1450 \mathrm{~g}$, and a gel was obtained corresponding to a leukocyte-poor PRFM of $1.5 \mathrm{~mL}$ containing approximately $5 \mathrm{x}$ platelet/ fibrin, according to the manufacturer (Simon et al., 2009).

\section{In vitro study}

Constructs were prepared with goat cartilage fragments. Articular cartilage pieces were harvested from femoral trochleae of 7 adult female Roccaverano goats during the in vivo part of the experiment, from the animals assigned to control groups.

Care was taken in order to remove all debris of the calcified cartilage and the subchondral bone from the specimens. Cartilage pieces from both trochlear defects of the same animal were pooled together, rinsed with sterile saline, transferred to a Petri dish and manually minced into small cuboidal fragments (less than $1 \mathrm{~mm}^{3}$ ) in sterile conditions with a sharp No. 15 scalpel in the presence of phosphate-buffered saline (PBS) (Celbio, Pero, Milano, Italy). A non-woven esterified HA-derivative felt (Hyaff-11, FIDIA Advanced Biopolymers, Abano Terme, Italy) was trimmed to pieces of $0.7 \mathrm{~cm}^{2}$. Two sheets were layered in a culture dish. Approximately $15 \mathrm{mg}$ of cartilage fragments were evenly seeded onto the membrane and were retained with a thin coating of approximately $50 \mu \mathrm{L}$ of fibrin glue (Tissucol, Baxter AG, Vienna, Austria) using thrombin (400-625 units $/ \mathrm{mL}$ ) that was previously diluted to $1: 4$ with calcium chloride $(36-44 \mu \mathrm{mol} / \mathrm{mL})$. A $200 \mu \mathrm{L}$ volume of PRFM (Cascade) was then placed on top of the cartilage fragments. A total of 6 constructs per animal were prepared.

All constructs were cultured at $37{ }^{\circ} \mathrm{C}$ in a humidified atmosphere containing $5 \% \mathrm{CO}_{2}$. Culture medium contained high glucose (4500 mg/L) DMEM (Celbio, Pero, Milan, Italy) with $10 \%$ foetal bovine serum (Sigma Chemical Co., St. Louis, MO, USA), HEPES (10 mM) (Sigma), nonessential amino acids $(0.1 \mathrm{mM})$ (Sigma), L-proline (20 ng/mL) (Sigma), ascorbic acid $(50 \mu \mathrm{g} / \mathrm{mL})$ (Sigma), 10,000 units Penicillin, $10 \mathrm{mg}$ Streptomycin in $0.9 \%$ sodium chloride (Sigma). Culture medium was changed three times per week.

After $15 \mathrm{~d}, 1$ month and 2 months, constructs were retrieved from cultures, fixed in formalin, embedded in paraffin, and processed for histological analysis. Tissue sections were stained for Haematoxylin/Eosin and Alcian Blue. Type I (MAB3391, Millipore, Milan, Italy) and II collagen (MAB-10200, Immunological Science, Rome, Italy) immunohistochemistry was also performed on the specimens retrieved after 1 and 2 months.

\section{In vivo animal study}

18 adult female Roccaverano goats were used in this study. $10 \mathrm{~mL}$ blood samples were collected preoperatively to obtain autologous PRFM (Cascade ${ }^{\circledR}$ ), as described above. All animals were anaesthetised as follows: $10 \mathrm{mg} / 100 \mathrm{~mL}$ Acepromazine Maleate - Prequillan (Fatro S.p.A., Bologna, Italy ) at the dosage of $0.1 \mathrm{mg} / \mathrm{kg} 1 \mathrm{~h}$ before surgery; $10 \mathrm{mg} / 20 \mathrm{~mL}$ Propofol - Rapinovet (Intervet Italia Srl, Milano, Italy) at the dosage of $7 \mathrm{mg} / \mathrm{kg}$ at the induction of anaesthesia. After induction, anaesthesia was maintained with isoflurane - Isoflurane-vet $250 \mathrm{~mL}$ (100\% isoflurane) (Merial Italia S.p.A., Padova, Italy) for a percentage of 1-2.5\% of isoflurane inspired during the procedure and buprenorphine - Temgesic iv (Shering Plough S.p.A., Milano, Italy) $0.3 \mathrm{mg} / \mathrm{mL}$ at the dosage of 


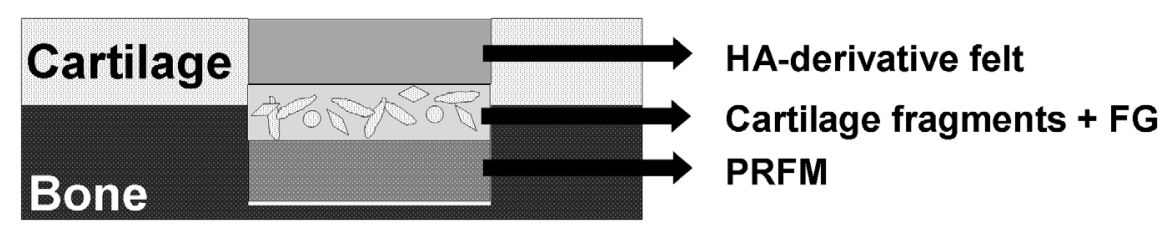

\section{Group 1}

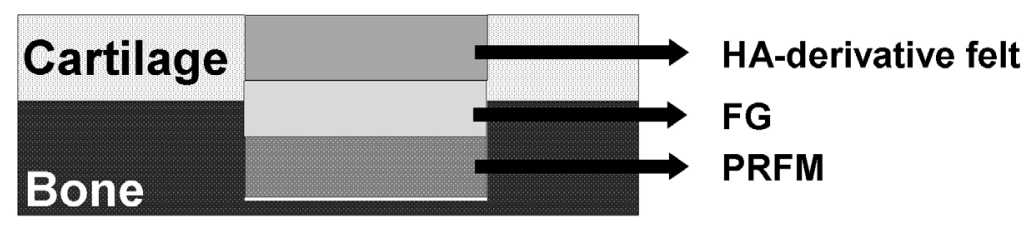

Group 2

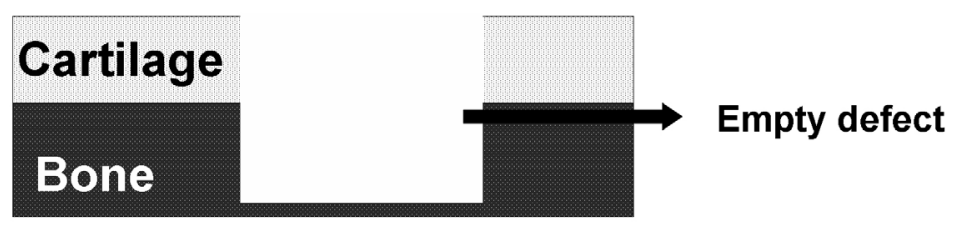

Group 3

Fig. 2. Study groups. Experimental groups were prepared with cartilage fragments: Group 1) cartilage fragments loaded onto the scaffold; Group 2) scaffold alone; Group 3) empty defect. FG, fibrin glue; HA, hyaluronic acid; PRFM, platelet-rich fibrin matrix.

$0.01 \mathrm{mg} / \mathrm{kg}$. At the end of anaesthesia, postoperative pain management was instituted with buprenorphine-Temgesic im (Shering Plough S.p.A.) $0.3 \mathrm{mg} / \mathrm{mL}$ at the dosage of $0.01 \mathrm{mg} / \mathrm{kg}$. Prophylactic antibiotic therapy was instituted as follows: tetracycline - Terramicina-ossitetracycline $92.7 \mathrm{mg} / \mathrm{mL}$ (Pfizer Italia SRL, Latina, Italy ) at the dosage of $10 \mathrm{mg} / \mathrm{kg}$ the day before the operation and every $24 \mathrm{~h}$ up to the sixth postoperative day; cefazolin - Cefazolina im $1 \mathrm{~g} / 4 \mathrm{~mL}$ (Mylan S.p.A., Milano, Italy) at the dosage of $20 \mathrm{mg} / \mathrm{kg} 1 \mathrm{~h}$ before surgery and every $12 \mathrm{~h}$ up to the second postoperative day.

Defects were prepared by exposing the femoral trochlea using a medial arthrotomy, thus dislocating the patella laterally. Unilateral trochlear models consisted of two large full-thickness osteochondral defects $(7 \mathrm{~mm}$ diameter; $3.5 \mathrm{~mm}$ depth), created in the central trochlear area of the right stifle joints with a minimum of $5 \mathrm{~mm}$ of separation between the 2 defects. In each goat, cartilage was collected from the defect areas before defect creation and manually minced in the presence of PBS, obtaining fragments of less than $1 \mathrm{~mm}^{3}$. Cartilage fragments were then pooled together to be used both for the in vitro culture and for the in vivo autologous implant in the experimental group (Group 1). A $7 \mathrm{~mm}$ diameter manual drill was used to create the defects. A slow and progressive manual drilling was performed for each defect. Debris were removed by the advancing of the spiral drill and with the help of multiple lavages with physiological solution during and after the drilling procedure. This allowed for a controlled and standardised penetration of the drill and avoided any major heat generation around the defect surface and any debris build-up. Consequently, the structural integrity and vitality of the bone and vessels surrounding the defect site was preserved, as evidenced by the absence of any fracture of bone at the rim of the lesion and by the amount of blood that appeared at the bottom of the defect site during the final drilling phase.

The dimensions chosen in this model were based on prior studies (Frisbie et al., 2006; Jackson et al., 2001) that showed that osteochondral defects of $6 \mathrm{~mm}$ diameter do not spontaneously heal. A depth of $3.5 \mathrm{~mm}$ enabled the removal of approximately $2-2.5 \mathrm{~mm}$ of underlying subchondral bone (Hunziker, 1999b; Ahern et al., 2009).

A total of 36 defects (for all goats used in the study) were created. Animals were randomised into 3 different groups: cartilage fragments plus scaffold (Group 1, experimental group), scaffold alone (Group 2), empty unfilled defects (Group 3) (Fig. 2).

Goat defects in Groups 1 and 2 were filled as follows: the defect was dried with a sterile sponge, and $90 \mu \mathrm{L}$ of autologous PRFM was manually placed at the bottom. In Group 1, autologous cartilage fragments, harvested from the two trochlear areas and pooled together, were evenly distributed at the surface of the autologous PRFM at a density of approximately $20 \mathrm{mg} / \mathrm{cm}^{2}$, based on previous studies (Lu et al., 2006; Frisbie et al., 2009). Approximately $20 \mu \mathrm{L}$ of fibrin glue (Tisseel, Baxter AG, Vienna, Austria; with thrombin previously diluted to 1:4 with calcium chloride) was added to stabilise the construct. A sheet of Hyaff-11 (diameter $7 \mathrm{~mm}$ ) was then added to seal the defect. Manual pressure on the surface of the constructs was applied to further stabilise the scaffold until the fibrin glue polymerisation was completed and the implant surface was even with the surrounding trochlear area. The wound was closed and a soft bandage was bound on the wound for the first 4-5 d. Postoperatively, all animals were allowed free-loading activity and free cage activity, and they were kept in a properly cleaned animal care facility. A single stall $(5 \mathrm{~m} \times 5 \mathrm{~m})$ was used to host each animal for the first 2 postoperative weeks; all animals were then kept 


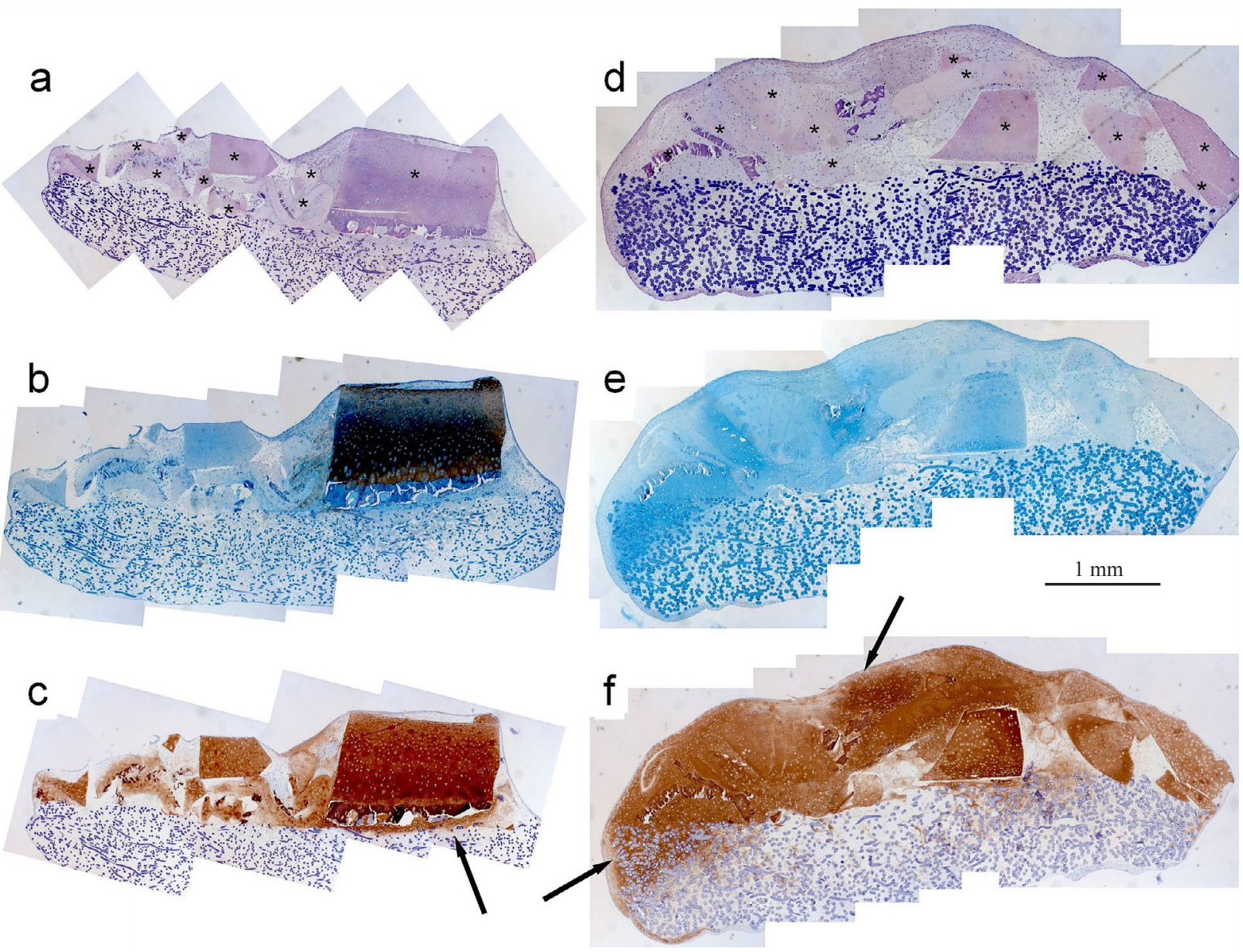

Fig. 3. Microscopic analysis of cartilage fragment-loaded constructs from goat femoral trochlea at 1 month (a,b,c) and 2 months (d,e,f); (a,d) haematoxylin-eosin staining; (b,e) Alcian Blue staining; (c,f) collagen type II immunostaining; the asterisk $(*)$ marks the cartilage fragments in $\mathbf{a}$ and $\mathbf{d}$; the arrows indicate the presence of neo-matrix positive for collagen type II, produced by the chondrocytes and located within the scaffold in $\mathbf{c}$ and $\mathbf{f}$. Histological figures were obtained by combining different microscopic images.

together in a common environment $(5 \mathrm{mx} 15 \mathrm{~m})$ up to the end of the follow-up period. Spontaneous rest and reduced movement of the animals were observed for the first 5-7 d. Generally, no sign of limping was observed after 8-10 d following surgery. We did not observe any difference of postoperative behaviour among the animals. Three goats died postoperatively and were excluded from the study. The remaining animals were humanely euthanised after 1 month ( 3 goats, 2 defects per group), 3 months ( 3 goats, 2 defects per group), 6 months ( 3 goats, 2 defects per group) and 12 months ( 6 goats, 4 defects per group). All animals were euthanised, following anaesthesia, using Tanax bottle $50 \mathrm{~mL}$ (Intervet Italia Srl) at the dosage of $0.1 \mathrm{~mL} / \mathrm{kg}$ by intracardiac injection.

Total joint health was assessed by gross-morphological evaluation, by observing the repair tissue filling, the presence of osteophytes and the inflammatory changes of the synovial membrane. At 1 year, the International Cartilage Repair Society (ICRS) form (ICRS Cartilage Repair Assessment) was used to collect macroscopic characteristics of the repair tissue (Kaul et al., 2012; Brittberg and Winalski, 2003) and each stifle joint was evaluated with the macroscopic scores of Little (Little et al., 2010).

For histological assessment, the distal femur was excised, fixed in $10 \%$ formalin and decalcified. Samples were then paraffin-embedded, sectioned with a microtome $(5 \mu \mathrm{m})$ and stained with Haematoxylin/Eosin and Alcian blue. Samples were also processed for immunohistochemistry analysis for type I and II collagen. Type II collagen immunohistochemistry was performed with MAB-10200 (Immunological Science). Each slide was blindly examined under a light microscope by 2 blinded observers. Samples were semi-quantitatively graded using the modified ICRS score (Liu et al., 2006), the modified O'Driscoll scale (Frisbie et al., 2009), and the microscopic scores of Little (Little et al., 2010). These scoring systems were based on the percentage of defect filling, articular surface continuity, restoration of osteochondral architecture, repair tissue integration, cellular morphology of articular cartilage regeneration, and matrix staining.

The superficial zone of repair tissue from 1 year specimens from Groups 1, 2 and 3, was biomechanically tested by nanoindentation (Franke et al., 2007). For positive 

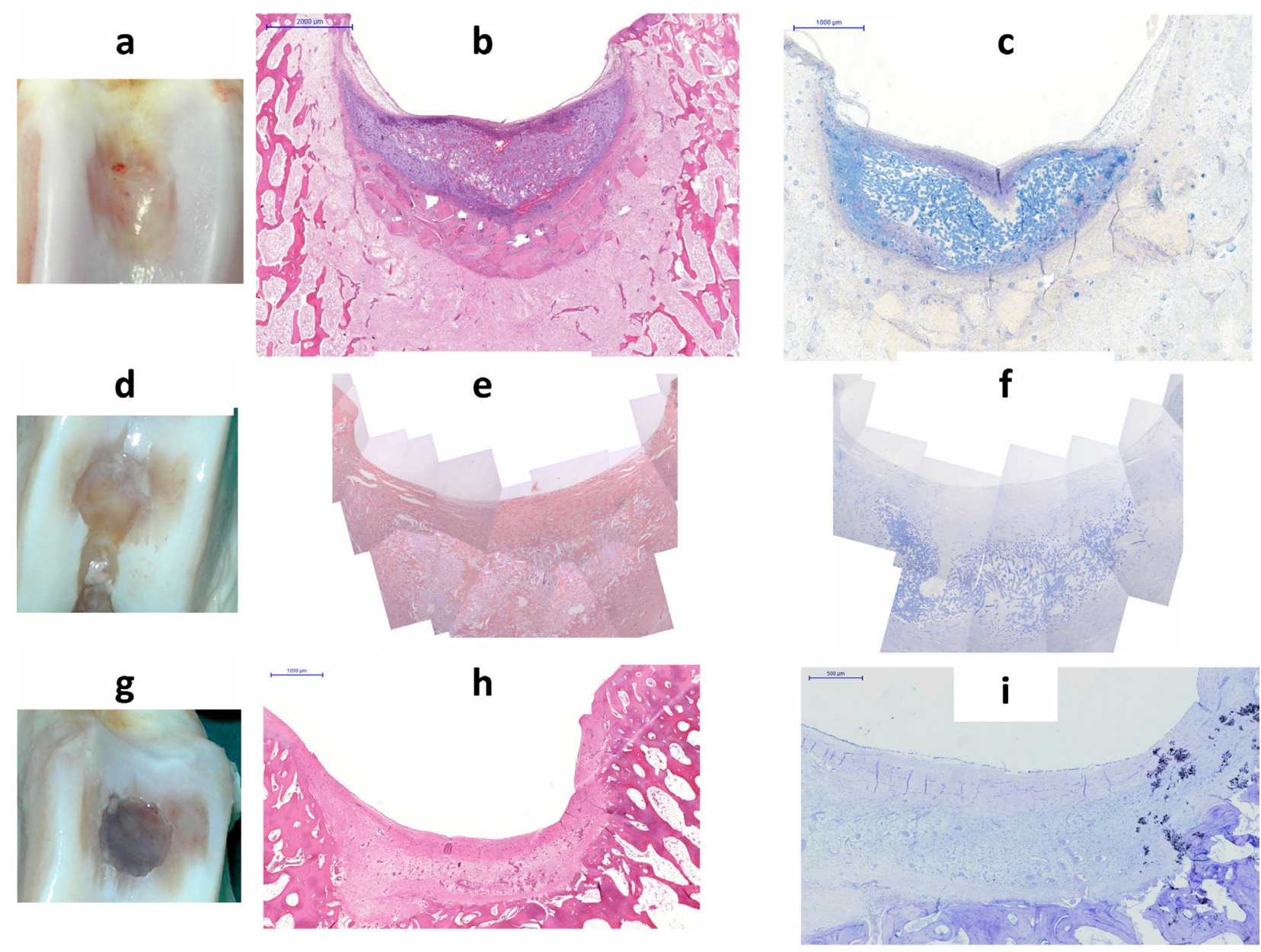

Fig.4. Macroscopic and microscopic views of repair tissue at 1 month post-implantation. Group 1: a,b,c; Group 2: d,e,f; Group 3: g,h,i. Macroscopic views (a,d,g); sections of the defect area stained with H/E (b,e,h), and Alcian Blue $(\mathbf{c}, \mathbf{f}, \mathbf{i})$. Histological figures $\mathbf{e}$ and $\mathbf{f}$ were obtained by combining different microscopic pictures. Cell infiltration of the scaffold can be observed in all groups, more markedly in Groups 1 and 2. In Group 1, cell are visible around the cartilage fragments, which were located at the deeper zone of the defect under the HA sheet, suggesting the potential contribution of cartilage chips to the repair. Cells are also present at the upper layer of the defect, likely deriving from the surrounding synovial tissue and from the cartilage at the perimeter of the defect. Cells are also visible both infiltrating the bottom of the defect and inside the scaffold, likely deriving from the bone marrow underneath and around the defect walls. In all three groups, the lowest amount of cells corresponded to the central zone of the defects. No clear matrix deposition was observed in any group.

controls, mechanical tests were also performed on trochlear cartilage samples from the contralateral stifle joint of Group 1 goats. From treated goat stifle joint, a representative osteochondral sample corresponding to the inferior half of the defect area was prepared using a miniature rotating saw. The same area was isolated from the trochleae of 2 contralateral stifle joints of Group 1 goats. Samples were transferred to PBS to prevent drying and stored at $4{ }^{\circ} \mathrm{C}$. Testing was performed within $72 \mathrm{~h}$ from harvesting. Nanoindentation was performed with a Nanoindenter XP (MTS, Eden Prairie, MN, USA) with a diamond indenter (Berkovich diamond tip) at room temperature. Samples were placed in a plastic chamber with the cartilage surface perpendicular to the indenter direction and secured to a metallic support. They were kept hydrated with saline prior to testing. The Berkovich tip was driven onto the specimen surface and the applied force and displacement obtained were recorded. Material properties were calculated from the load and depth of indentation. Hardness $(\mathrm{H})$ and Young's modulus (E) were calculated as a function of load and depth during the unloading phase of testing, with a maximal load of approximately $75 \mathrm{mN}$ and a maximal depth of $100 \mu \mathrm{m}$. Sample fractures of Groups 2 and 3 were observed beyond $40 \mu \mathrm{m}$ of Berkovich tip penetration; this compromised Young's modulus determination during the unloading phase for Groups 2 and 3. Mean values of Young's modulus (E) were then calculated for all samples on the loading curves, in a range of $1-40 \mu \mathrm{m}$ depth. This allowed for a comparative evaluation between groups, although in a limited range of tip penetration.

\section{Statistical analysis}

All data in text and figures are provided as means \pm SD. Results were analysed by a one-way Analysis of Variance (ANOVA) and Tukey's test. A $p<0.05$ was considered statistically significant. 
a

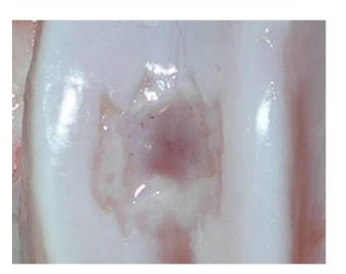

d

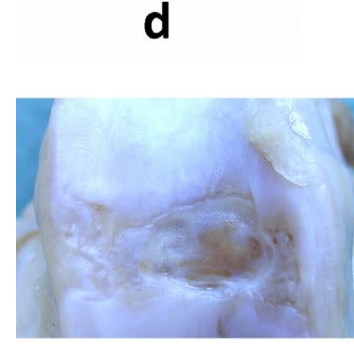

g

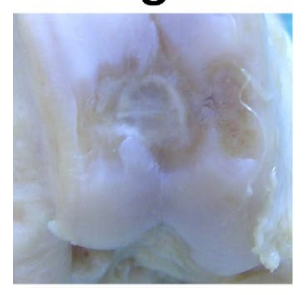

b

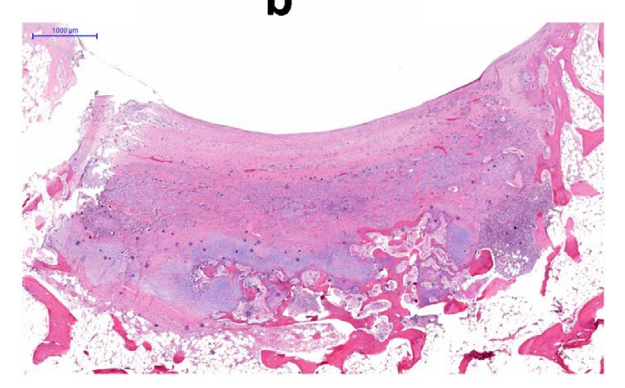

e
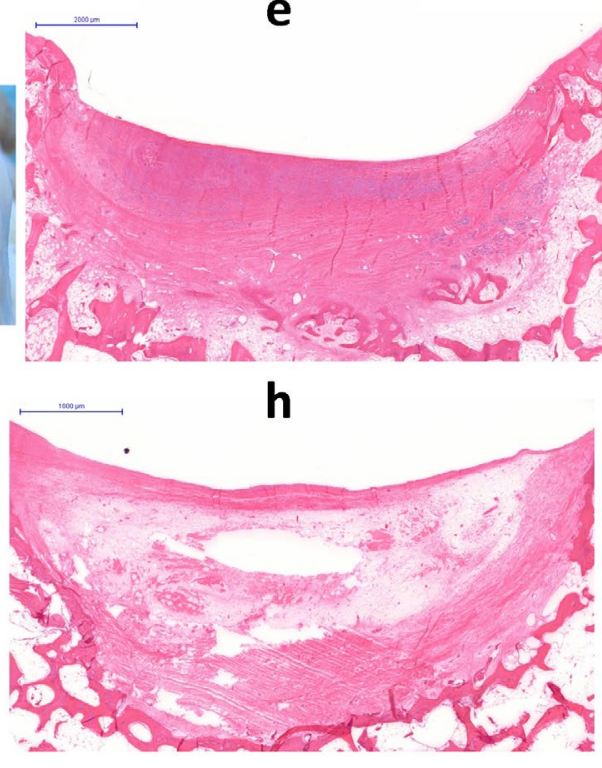
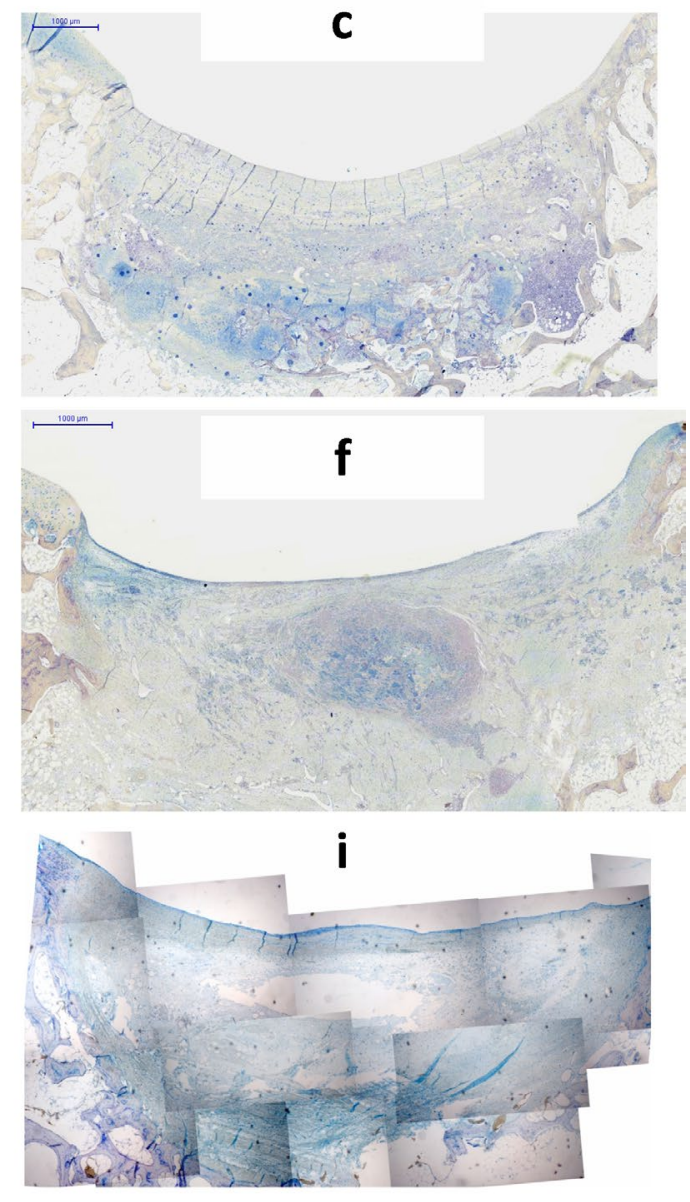

Fig. 5. Macroscopic and microscopic view of repair tissue at 3 months post-implantation. Group 1: a,b,c; Group 2: d,e,f; Group 3: g,h,i. Macroscopic views (a,d,g); sections of the defect area stained with H/E (b,e,h), and Alcian Blue (c,f,i). Histological figure i was obtained by combining different microscopic pictures. The repair tissue is irregular and poorly differentiated in all groups. A widespread cell infiltration is visible in all zones of the scaffold in Groups 1 and 2, the former showing higher cellularity at defect sites and inflammatory tissue around the defect area. Interposing areas of neo-matrix positive for type II collagen can be observed in Group 1 among the fragments.

\section{Results}

\section{In vitro study}

Chondrocyte outgrowth into scaffolds was evident at $15 \mathrm{~d}$ (data not shown) and increased at 1 and 2 months. Constructs loaded with cartilage fragments showed high cellularity after 1 month, while intense neo-matrix was evident within scaffold structures after 2 months. Migrated chondrocytes showed a rounded shape, surrounded by neo-matrix, after 2 months. The newly formed tissue between the fragments was positive for collagen type II immunostaining at 2 months (Fig. 3) and showed a weak positivity for collagen type I immunostaining.

\section{In vivo animal study}

Some major adverse events occurred during the in vivo study. Three animals died between day 30 and day 45 postoperatively due to acute infectious enteritis, despite the antibiotic prophylaxis, and were excluded from the study. Autopsies performed at the Animal Care Institute (CISRA) on the 3 goats did not show signs of thromboembolism in the mesenteric vessel. A total of 15 animals therefore completed the follow-up.
Three goats were euthanised at 1 month (with a total of 6 defects, 2 defects per group), 3 goats at 3 months (6 defects, 2 defects per group) and 3 goats at 6 months (6 defects, 2 defects per group) in order to qualitatively evaluate the repair process. Additionally, in order to perform semi-quantitative evaluation (ICRS, O'Driscoll and Little score) and mechanical testing (nanoindentation), 6 goats were euthanised at 1 year ( 12 defects, 4 defects per group).

At 1 month (Fig. 4), gross-morphological evaluation on specimens showed a depressed surface of repair tissue, pale in appearance, particularly marked in Groups 2 and 3. Gross appearances of Group 1 and 2 were similar due to the presence of the scaffold, still largely unresorbed at the surface of the defect site. Mild synovial changes were observed in all operated stifle joints. The irregular repair tissue corresponded histologically to a cell infiltration of the scaffold in Groups 1 and 2. Cells were scarce at the central zone of the defect in all three groups.

Various cells were observed as contributors to the repair. These were seen around the cartilage fragments, at the upper layer and at the bottom of the defect, along with cells visible inside the scaffold. No clear matrix 
a

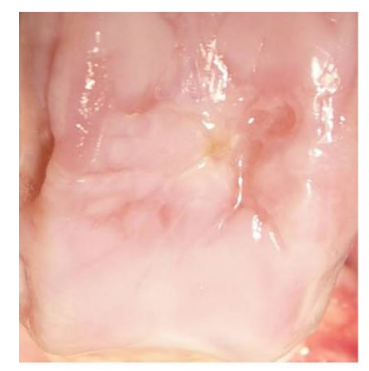

d

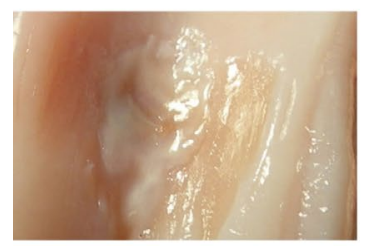

g

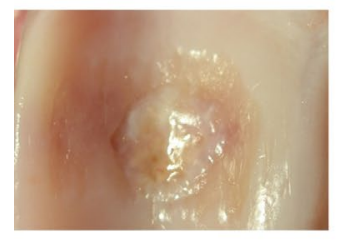

b

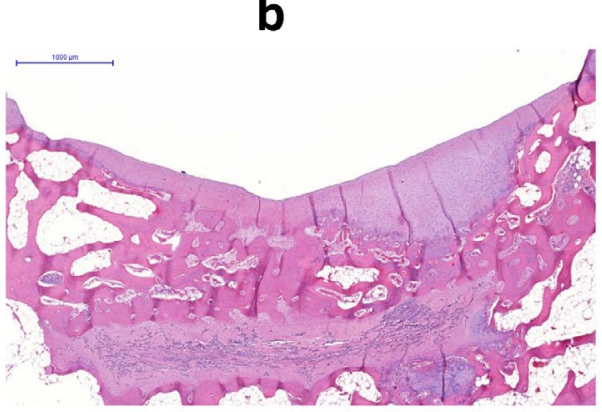

e
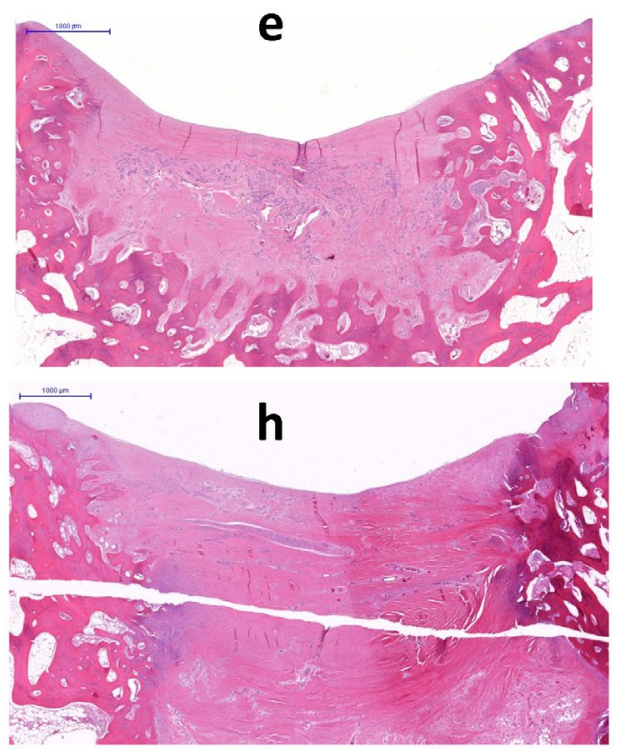
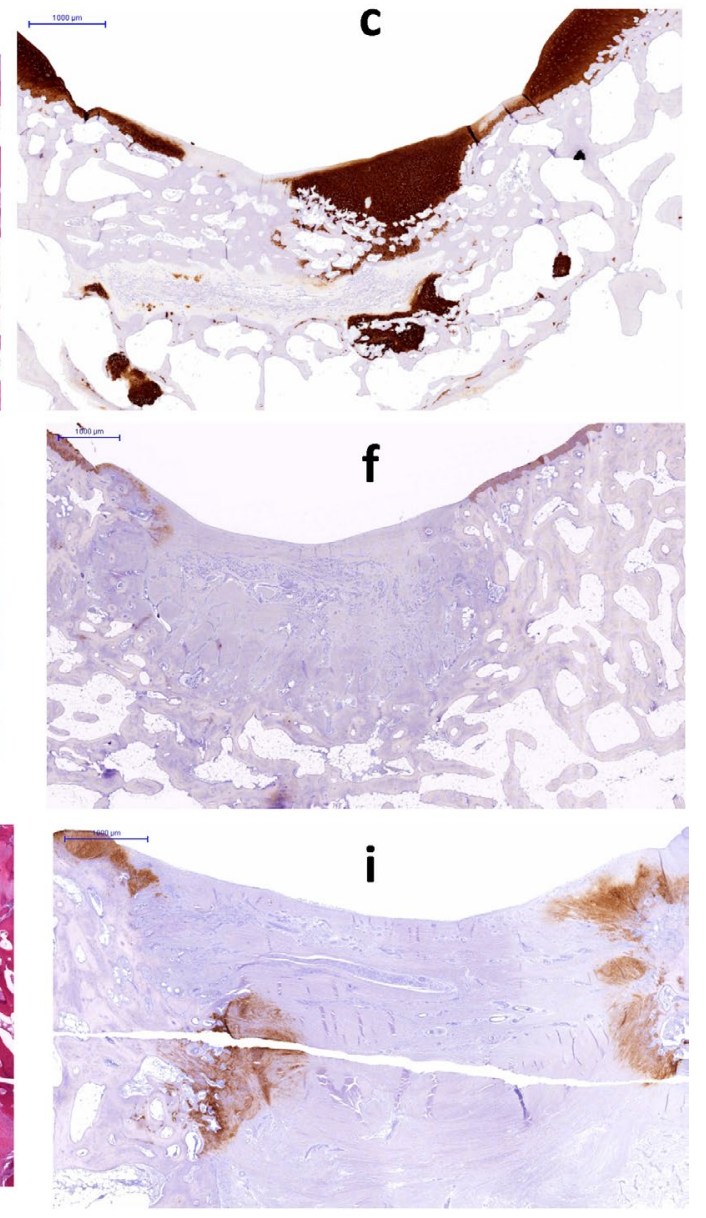

Fig. 6. Macroscopic and microscopic view of repair tissue at 6 months post-implantation. Group 1: a,b,c; Group 2: d,e,f; Group 3: g,h,i. Macroscopic views (a,d,g); sections of the defect area stained with H/E (b,e,h), and immunohistochemistry for collagen type II $(\mathbf{c}, \mathbf{f}, \mathbf{i})$. Immature fibrous tissue and areas of hypercellularity are present in all groups. In Group 1, neo-matrix positive for type II collagen is visible at the superficial and central portions of the defects, along with remnants of the Hyaff membrane, while cartilage fragments are scarcely detectable.

deposition was observed in any group. In Group 1, cartilage fragments, which were located at the deeper zone of the defect, appeared under the HA sheet, surrounded by a large number of cells, infiltrating both the space between the fragments and the lower part of the HA sheet. Repair tissue of untreated defects was similar to the early healing process in deep osteochondral lesions in goat models, with the formation of fibrous tissue, as reported in the literature (Jackson et al., 2001). Neither fracture sign nor major vascular compromise in the host bone were observed in any group.

At 3 months (Fig. 5), gross-morphological evaluation in all groups continued to show an uneven and depressed layer of repair tissue. At the periphery of the defect, repair tissue was thicker in Group 1, showing a white colour similar to the surrounding cartilage. Minor synovial changes were observed in all groups. Histologically, the repair tissue was still irregular and poorly differentiated in all groups. A widespread cell infiltration was observed in all zones of the scaffold in Groups 1 and 2.

Group 1 showed high cellularity at defect sites, with some inflammatory tissue around the defect area; cartilage fragments were still detectable, although the cell migration created patchy over-stained interposing areas of matrix positive for type II collagen among the fragments. In empty defects (Group 3) and in Group 2 samples, these areas were not detectable. Repair tissue showed a greater inflammatory reaction in Group 2 around the defect area, while in specimens of Group 3, a remodelling of the natural fibrin clot was observed, with formation, in some cases, of a central cyst-like structure, as also observed in previous studies (Jackson et al., 2001).

At 6 months (Fig. 6), the repair process was still macroscopically irregular and depressed in all groups. Small osteophytes and surface irregularities were observed in all stifle joints along with mild macroscopic inflammatory changes of the synovial membrane. Immature fibrous tissue and areas of hypercellularity were observed at histological evaluation in all groups In Group 1, cartilage fragments were scarcely detectable; areas of neo-matrix positive for type II collagen were observed at the superficial and central portions of the defects, with staining similar to that of the native cartilage at the border of the defect. In Groups 1 and 2 , remnants of the Hyaff-11 membrane were still present. In the control Groups 2 and 3, no collagen type II-positive areas were observed.

After 1 year (Fig. 7), gross morphological evaluation showed better quality repair tissue in defects treated with 


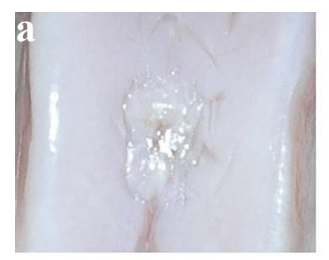

A
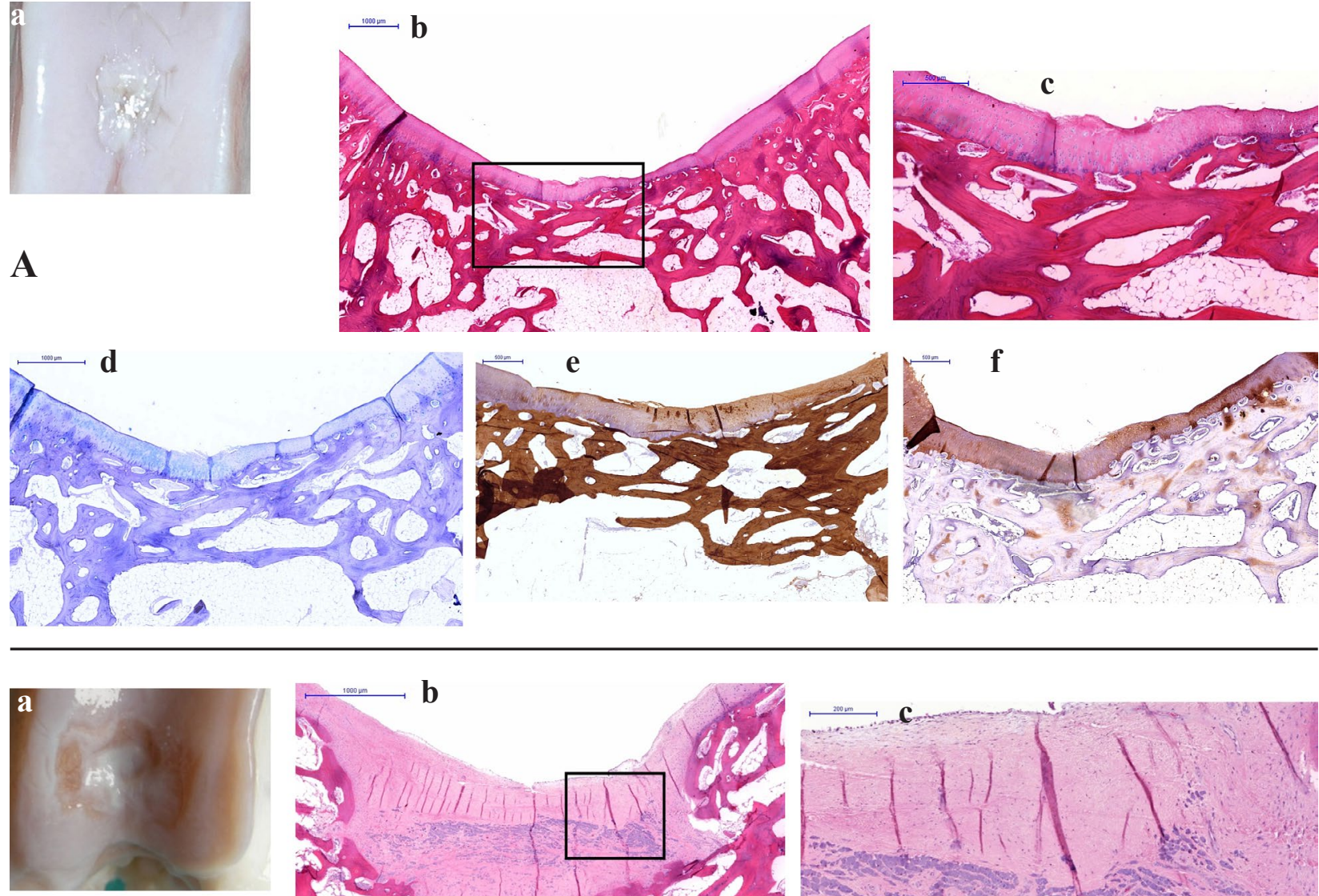

B
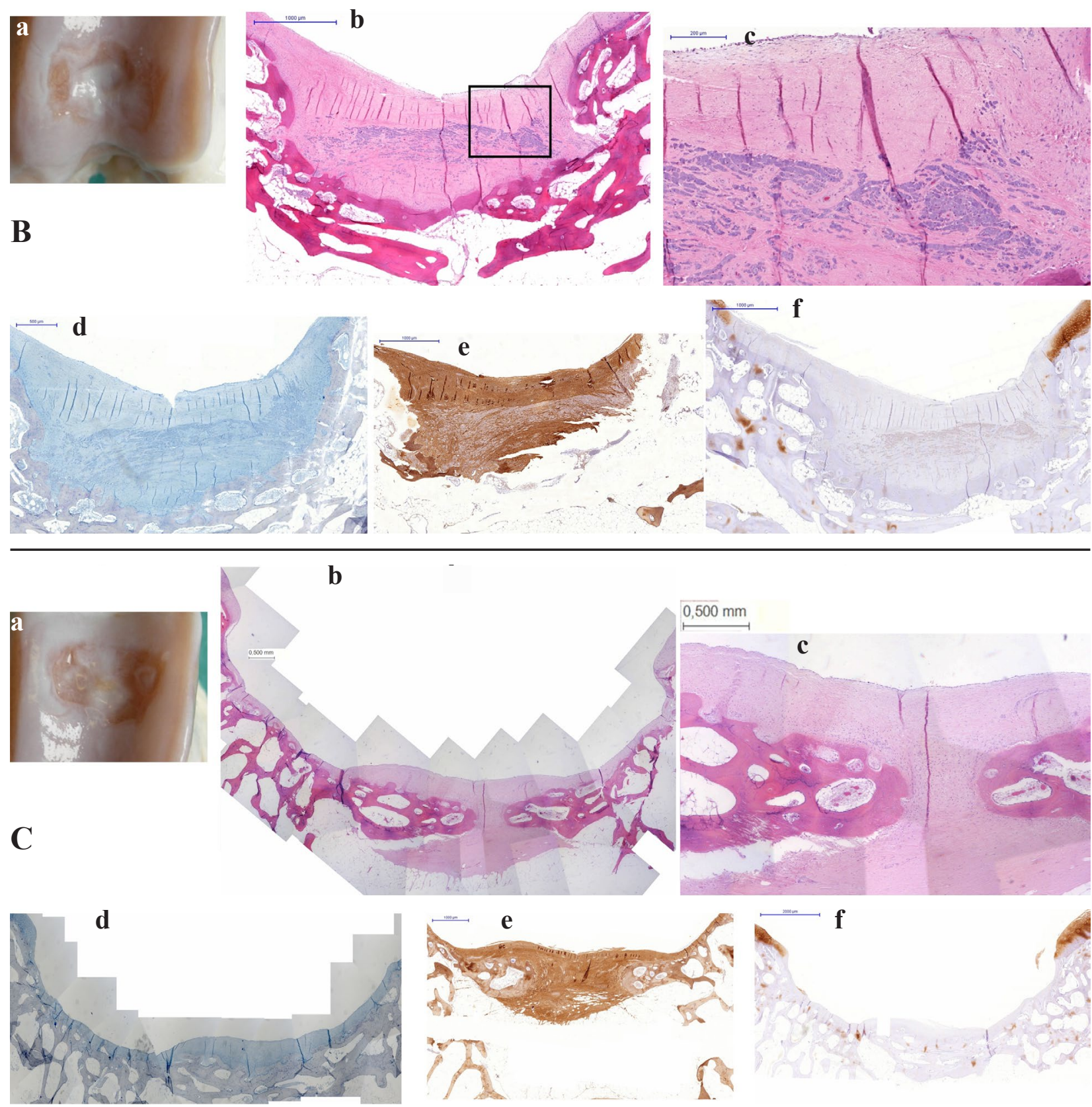

Legend on next page 
Fig. 7. (previous page) Macroscopic and microscopic view of repair tissue at 1 year post-implantation. A: Group 1, B: Group 2; C: Group 3. Macroscopic views (a). Sections of the defect area stained with H/E (b,c), Alcian Blue (d), and immunohistochemistry for collagen type I (e) and type II (f). Histological figures $\mathbf{C b}$ and $\mathbf{C d}$ were obtained by combining different microscopic pictures. Some features of hyaline-like cartilage can be observed in repair tissue of Group 1, as the presence of type II collagen upon immunostaining in the superficial layer of the repair tissue, the presence of type I collagen in the newly formed subchondral bone, the restoration of osteochondral orientation, and, in some areas, the columnar arrangement of chondrocytes. Fibrous-fibrocartilaginous tissue is predominant in Group 2, along with remnants of the Hyaff-11 membrane in the central areas of the defect surrounded by inflammatory infiltration; incomplete subchondral bone restoration is also visible. Group $\mathrm{C}$ repair is mainly constituted by a homogeneous fibrocartilage repair tissue without columnar organisation surrounding a layer of newly formed subchondral bone; neomatrix in the upper layer lacks any type II collagen-positivity.

cartilage fragments along with scaffolds (Group 1). Repair tissue was white and mostly even with the surrounding cartilage, although some fissures and small depressed areas were observed at the periphery of the defects. In Groups 2 and 3, some even areas with whitish repair tissue were also present, but most of the defect site was filled with rough, uneven tissue. Synovial tissue proliferation and osteophyte formation were evaluated following the macroscopic scoring method of Little (Little et al., 2010). No major synovial reactions (i.e score $>1$ ) were detected in any of the three groups, while mild osteophyte development (i.e. score $=1$ ) was observed around the trochlear areas and around the medial femoral condyles in most of the specimens of the three groups. However, no significant differences were observed among all stifle joints of the experimental animals regardless of the treatment used.

Evaluation of the repair tissue showed higher scores for defects treated with cartilage fragments along with scaffolds (Group 1), both macroscopically and microscopically (Fig. 8). Macroscopic ICRS Cartilage Repair Assessment showed significant differences between Group 1 and both control groups in the "Degree of Defect Repair" and in the "Macroscopic Appearance", while no significant differences were noticed between untreated defects (Group 3) and defects treated with scaffolds alone (Group 2). The same statistical trend was observed in the modified microscopic ICRS score, in the O'Driscoll microscopic score, and in the microscopic score of Little. In the latter, significant difference between Group 1 and both control groups was observed in section A (Structure), section D (Interterritorial Toluidine blue) and section E (Tidemark/calcified cartilage/subchondral bone), while in section B (Chondrocyte density) a significant difference was noticed between Groups 1 and 3 and between Groups 2 and 3.

Repair tissue of Group 1 showed: i) some features of hyaline-like cartilage with normal to moderate matrix staining (Fig. 7Ab and d); ii) the presence of type II collagen upon immunostaining in the superficial layer of the repair tissue (Fig. 7Af); iii) the presence of type I collagen in the newly formed subchondral bone, along with some traces also in the upper layer of the cartilaginous repair tissue (Fig. 7Ae); iv) restoration of osteochondral complexes and, in some areas, columnar arrangement of chondrocytes (Fig. 7Ac). Nevertheless, some irregular bonding adjacent to the healthy cartilage was observed.

Treatment with scaffolds alone (Group 2) mainly led to the formation of central fibrous-fibrocartilaginous tissue with some remnants of the Hyaff membrane in the central areas of the defects (Fig. 7B). Peripheral areas of cartilage matrix were often present and were positive for type II collagen, suggesting a centripetal repair from surrounding healthy cartilage. Inflammatory infiltration was still detected around the Hyaff-11 membrane; and bone was present at the bottom of the defects, around the residual scaffold.

Empty defects were filled with a homogeneous fibrocartilage repair tissue without columnar organisation (Fig. 7C); some irregular gaps at defect borders were observed, occasionally with the exposure of subchondral bone. Group 3 fared better than Group 2 for subchondral bone restoration, but lacked any type II collagen-positive matrix at the peripheral areas.

Nanoindentation of goat samples after 1 year demonstrated interesting differences between groups (Fig. 9). Group 1 behaved in a considerably different manner from control Groups 2 and 3. From the unloading curve, hardness of Group 1 was greater than Groups 2 and 3, and mean values were closer to healthy trochlear cartilage than any of the control groups, although mean hardness $(\mathrm{H})$ of healthy cartilage was significantly different from that of all groups $(p<0.05)$. Young's modulus of Group 1 was similar $(p>0.05)$ to healthy cartilage. Mean Young's modulus, as determined from the loading curves, revealed similar findings. A significant difference $(p<0.05)$ was still observed between mean values of healthy cartilage and mean values of all three Groups, but the group treated with cartilage fragments loaded onto scaffolds (Group 1) reached values superior to those of control Groups 2 and $3(p<0.05)$, and was the most similar to that of healthy cartilage (Fig. 9).

\section{Discussion}

In the present study, we have demonstrated that longterm osteochondral repair is made feasible using cartilage fragments embedded in a hyaluronic acid/PRFM/fibrin glue scaffold in a goat model. This method is distinct from aforementioned studies because it relies on a hyaluronic acid, fibrin glue and autologous PRFM scaffold to obtain chondrocyte migration from autologous cartilage fragments.

The hyaluronic acid-derived membrane, Hyaff-11, was chosen for its well-known chondrogenic and adhesive properties (Cavallo et al., 2010; Kon et al., 2009). In this 


modified ICRS (max. 22)
1) percentage defect filling
2) Articular surface continuity
3) Restoration of osteochondral architecture
4) Repair tissue integration
5) Cellular morphology of articular cartilage
6) Matrix-staining (Metachromasia) col2 positivity
modified O'Driscoll (max. 28)
1) Cellular morphology
2) Alcian Blue (Matrix) staining
3) Surface
4) Structural integrity
5) Thickness
6) Bonding to adjacent cartilage
7) Reconstruction of subchondral bone
8) Inflammatory response in subchondral bone
region
9) Hypocellularity
10) Chondrocyte clustering
11) Freedom from degenerative changes in
adjacent cartilage

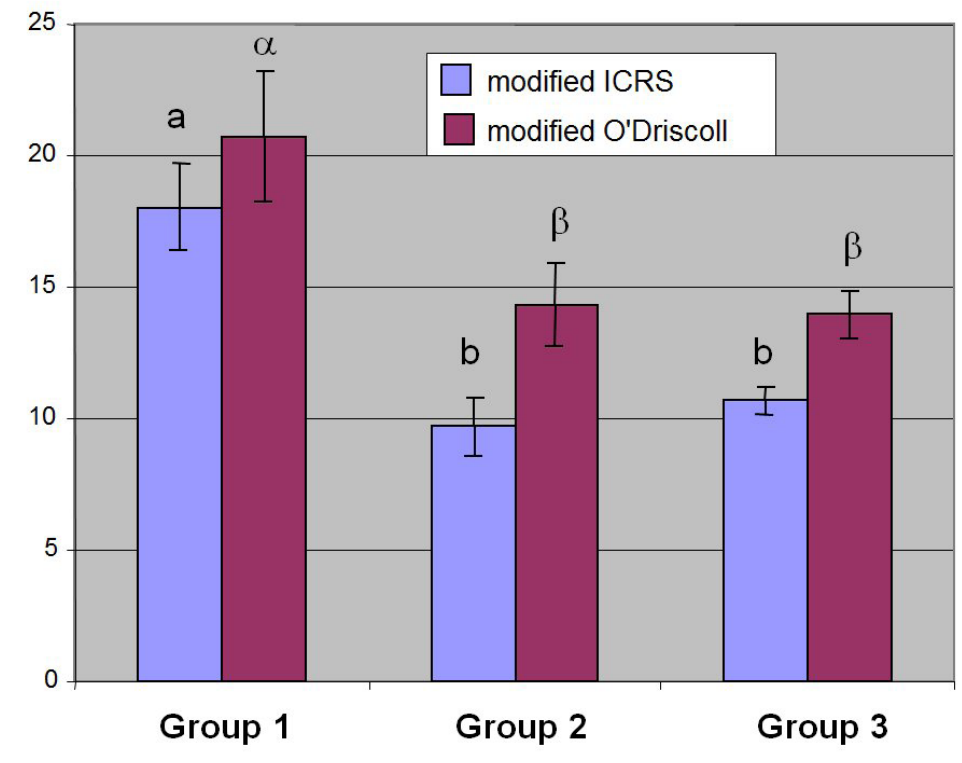

Fig. 8. Semi-quantitative histology scores using the modified ICRS score (Liu et al., 2006) and the modified O'Driscoll scale (Frisbie et al., 2009) at 1 year. Values with different superscripts differ at $p<0.01$; in particular, normal letters $\mathrm{a}$ and $\mathrm{b}$ refer to ICRS score (blue bars), while Greek letters $\alpha$ and $\beta$ refer to O'Driscoll scale (red bars).

model, it also worked well in conjunction with fibrin glue for coverage of the defect, and no membrane dislodgements were observed. A single Hyaff-11 membrane was sufficient to cover the defects during the in vivo experiment. On the other hand, in the in vitro study, a single layer was inadequate to contain all migrating cells, as during the early set-up phase of the study we observed a considerable number of cells at 1 month attached to the plastic dishes. Therefore, two sheets of HA membrane were used as a barrier in the study design, in order to avoid any significant cell migration from the construct to the Petri dish.

The Cascade-PRFM was chosen as a bioactive mouldable component of the scaffold. The Cascade technique has several advantages. It enables reduction of the damage to platelets during extraction, due to the absence of bovine thrombin in the production process (Carroll, 2005), producing a gel-like matrix with significantly higher number of platelets (approximately 5x) (Simon et al., 2009) in the end-product, compared to that of peripheral blood. The high capture efficiency of this commercial system was convenient for the design of the in vivo animal study, because it allowed for using smaller blood volumes compared to that of other commercial systems (i.e. Biomet GPS III) (Castillo et al., 2011). This end-product is a platelet derivative with low content of leukocytes; this was also considered favourable, as data from the literature suggested that anabolism requires low levels of leukocytes and the presence of high leukocytes concentration may increase catabolic signalling molecules (Sundman et al., 2011). Additionally, this PRFM contains higher concentrations of growth factors (e.g. TGF- $\beta 1$ ) compared to simple blood clots, and allows for temporary defect filling while delivering mitogenic factors from autologous platelets up to several days after the preparation, as shown in previous studies (Visser et al., 2010). These factors have also been shown to enhance tendon repair in vivo in animal models (Sarrafian et al., 2010). Moreover, anti-inflammatory properties have been recently attributed to the presence of other agents, for example the hepatocyte growth factor (Bendinelli et al., 2010). Furthermore, the end-product is a material that can be moulded in order to facilitate surgical application as the high fibrin content makes the matrix a natural scaffold with the ability to assist the ultimate repair of the lesions (Sánchez et al., 2007).

For the scaffold preparation, a small quantity of commercial fibrin glue (Tisseel, Baxter) was applied in order to stabilise cartilage fragments under the HA membrane. This was supported by in vitro observations showing the effect of fibrin glue in facilitating the migration of chondrocytes out of cartilage fragments in the first phases of scaffold colonisation. A 1:4 thrombin dilution compared to the original commercial preparation was chosen in order to obtain a large pore three-dimensional structure; this created spatial continuity between fragments, thus enabling free movement of cells. The fibrin glue can therefore be considered as a wrapping material for the cartilage chips and a bridging material between the HA-felt and the PRFM. As shown in other in vivo studies (Deponti et al., 2012; Lewis et al., 2009; Peretti et al., 2006; Peretti et al., 2001; Peretti et al., 2000), we did not observe any major inflammatory reactions in animal models, supporting the use of fibrin glue as a component of the scaffold.

In this study, cartilage fragments were harvested in each goat, during surgery, from the cartilage layer surrounding the two trochlear areas corresponding to the full-thickness osteochondral defect sites. They were pooled together and 


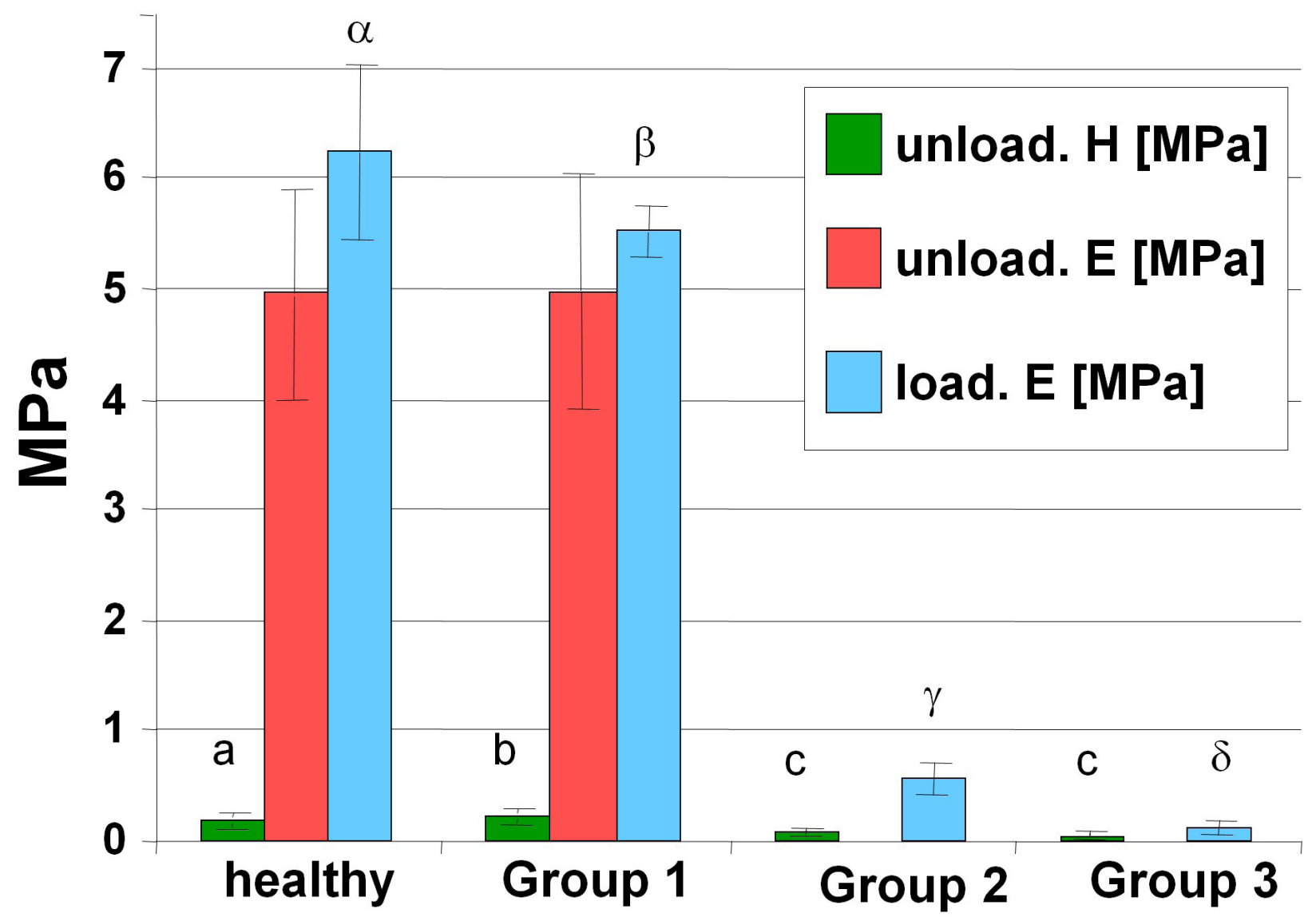

\begin{tabular}{|c|c|c|c|c|}
\hline \multicolumn{5}{|c|}{ from unloading curves } \\
\hline & healthy & Group 1 & Group 2 & Group 3 \\
\hline \multicolumn{5}{|c|}{$\mathrm{H}$ [MPa] } \\
\hline Mean & 0.18 & 0.23 & 0.08 & 0.05 \\
\hline SD & 0.06 & 0.06 & 0.01 & 0.01 \\
\hline \multicolumn{5}{|c|}{$\mathrm{E}$ [MPa] } \\
\hline Mean & 4.94 & 4.97 & * & * \\
\hline SD & 0.92 & 1.06 & * & * \\
\hline \multicolumn{5}{|c|}{ from loading curves } \\
\hline & healthy & Group 1 & Group 2 & Group 3 \\
\hline \multicolumn{5}{|c|}{ E [MPa] } \\
\hline Mean & 6.22 & 5.51 & 0.56 & 0.10 \\
\hline SD & 0.82 & 0.23 & 0.17 & 0.09 \\
\hline
\end{tabular}

Fig. 9. Nanoindentation of goat samples at 1 year. Healthy, healthy cartilage; unload. H, Hardness as measured during the unloading phase; unload. E, Young's modulus as measured during the unloading phase; load. E, Young's modulus as measured during the loading phase of testing; *, samples fracture during testing; SD, standard deviation. Values with different superscripts differ at $p<0.05$; in particular, normal letters a, b, c refer to hardness " $\mathrm{H}$ " (green bars), while Greek letters $\alpha, \beta, \gamma$ and $\delta$ refer to Young's modulus determined from the loading curves "load E" (blue bars). 
then used for the in vitro explant culture and the in vivo implant in Group 1. Thus, the source for the repair was constituted of cartilage fragments originating from both the upper and the lower trochlear defect. This allowed for eliminating, both in the in vitro and the in vivo steps, any potential different contribution to the repair of the chips deriving from different trochlear sites, as pointed out by a recent study by Salzmann et al. (2011).

The construct components were positioned in order to keep the same spatial orientation between the in vitro and in vivo part of the experiment, maintaining the cartilage chips and the fibrin glue in the middle of the construct and in contact with the PRFM on one side and with the HA felt on the opposite side. Indeed, in vivo, the PRFM was placed at the bottom of the goat trochlear osteochondral defects, the cartilage chips were wrapped in a small quantity of fibrin glue and placed in the middle, and the Hyaff-11 membranes at the top, due to the position of the defects and the gravity forces acting during the stance phase of the animal. For the in vitro part, an inverted spatial distribution was used, placing the Hyaff-11 membranes at the bottom of the Petri dishes, the mixture of chips and fibrin glue in the middle and the PRFM was placed at the top of the constructs.

The in vitro results showed the natural tendency of chondrocytes, once freed from the surrounding matrix, to migrate away from cartilage chips, in a standard non-chondrogenic culture medium. Indeed, our findings confirmed the initial hypothesis that the outgrowth of chondrocytes, derived from chondral fragments obtained by mechanical fragmentation of articular cartilage, allowed for the production of a newly synthesised matrix around the fragments and inside the Hyaff felt. This neoformed tissue was mostly originating from the migrated chondrocytes and showed features similar to those of articular cartilage, such as the overall predominance of collagen type II staining. These in vitro results are consistent with two previously published studies by Bonasia et al. (2011), in which adult and juvenile chondral fragments were cultured on a hyaluronic acid scaffold, and Lu et al. (2006). In the latter, human and bovine cartilage fragments were used both in explant cultures and in a heterotopic implant in SCID mice, after being seeded in scaffolds made of polyglycolide/ non-woven felt or polyglycolide/polycaprolactone foam reinforced with polydiaxanone mesh, with a coating of fibrin glue. These observations were the premise for developing an in vivo cartilage fragment-based technique for osteochondral repair.

Following previous evidence from preclinical animal models of trochlear defects in rabbits (Madry et al., 2005; Marmotti et al., 2012; Ueblacker et al., 2007), goats (Lu et al., 2006), pigs (Peretti et al., 2006), and horses (Frisbie et al., 2009), critically-sized trochlear osteochondral lesions were created to avoid spontaneous healing of smaller defects, as previously shown by Jackson and Ahern (Jackson et al., 2001; Ahern et al., 2009). This site has been widely used in the literature, and represents a valuable preclinical model being subjected both to shear forces, that may negatively influence the reparative process, and to compressive load during the stance and gait of animals, which have a prevalent flexed position of the stifle joint. Furthermore, it allows also for an easy surgical approach to a large area where multiple defects could be created. Indeed, for each unilateral trochlear model two defects were created at the upper and lower trochlear areas. It is known that patellar excursion generates different load bearing between the upper and lower trochlear areas (Salzmann et al., 2011). Thus, the three treatment groups $(1,2$ and 3$)$ were randomised to the two defect positions during the surgical procedure, in order to lessen the bias that could be generated by the variable loads imposed on the repair tissue by the patella during the tracking along the femoral groove, and so avoiding the potentially different contribution of the two defect sites to the repair process.

A depth of $3.5 \mathrm{~mm}$ was chosen to simulate a human clinical setting of osteochondral lesions. As previously shown, lesions beyond $3.5 \mathrm{~mm}$ in goats would lead unquestionably to a violation of the subchondral bone (Hunziker, 1999b; Custers et al., 2009; Ahern et al., 2009) during defect drilling, with extensive bleeding and subsequent involvement of an abundance of different cell types, growth factors and signalling substances from bone, bone marrow space and its vasculature. In this regard, the methodology of creating the defect can have a significant impact on the potential of the biological response of the surrounding host tissue bed. In our study, we have chosen a manual drill with multiple lavages. With this technique, defects were created in a natural way by using a slow speed of penetration and by removing any visible debris during the defect creation through continuous irrigation with physiological solution. This allowed for a standardisation of the procedure of defect creation preserving the integrity of the surrounding tissue, avoiding major vascular occlusion by debris build-up and significant temperature increase during defect drilling. A possible alternative would have been to adopt a more physio-pathological "fracture method" as that used in the OATS procedure, in which an osteochondral bone plug is fractured off the subchondral bone. However, even if this "fracture technique" also represents a good biological duplication of osteochondral lesions, it would have presented more difficulties in an experimental setting related to the standardisation of the method.

In this large animal model, we verified the in vivo repair potential of autologous cartilage fragments embedded in hyaluronic acid, PRFM and fibrin glue scaffold. For control conditions, we used the whole scaffold alone and the empty defect. Although the scaffold itself was made by assembling different components, we have considered this as an entire element, and we did not further separate any of the single scaffold constituents into different control groups. Moreover, in a clinical setting, some of the components of the scaffold are often associated. This is valid, for example, for the fibrin glue with the HA membrane, as the fibrin acts as a biological glue for HA, thus representing a single complex unit. Additionally, we ran in parallel the in vitro and the in vivo study with the same design.

Generally, a slow and incomplete overall repair process was observed in all groups. This is consistent with the cartilage repair obtained with cell-based tissue engineering processes (Knutsen et al., 2007; Brittberg et al., 2001). Up to 6 months postoperatively, immature tissue filled the 
major part of the defects, as confirmed by the persistent presence of the HA membrane in both Groups 1 and 2 . Cartilage fragments in the experimental Group 1 were found to be located at deeper zones of the defects already at the earlier time points. This was presumably due to the mouldable and resorbable nature of PRFM, allowing for a deepening of the fragments inside the matrix following implantation. This also implied that the fragments at the lower defect zone underwent a slower absorption during the natural bone repair process. In this regard, further optimisation of the implant could involve the use of a stiffer matrix, to obtain a more rigid supporting structure for the cartilage fragments, thus allowing for their homogeneous distribution directly under the HA sheet at the superficial layers of the defects. Nevertheless, we can state that the fragments were positively involved in the cartilage repair process, as the samples of Group 1 achieved an improved repair compared to that of the other groups at 6 months and 1 year. However, we cannot identify the role of these fragments in the entire repair process. In fact they may represent the cell source for the repair process, or indeed they could be the releasing source of conditioning factors, guiding the migrating cells from the surrounding tissue to assume a chondrocyte phenotype, or a combination of both.

At the end of follow-up, morphological assessment showed no major synovial changes and only mild osteophyte formation in all groups, without any difference despite the treatment used. This suggests that the mild inflammatory process developed in the operated joints did not exert considerable influence in the osteochondral repair process. The end-term histological assessment of the defects demonstrated that cartilage fragment-loaded scaffolds led to a functional repair tissue with some hyaline-like features. Indeed, after 1 year, Group 1 showed an improved repair tissue with higher scores compared to those of the controls, with the presence of proteoglycans and areas of matrix positive for collagen type II. No relevant remnants of HA membrane were detectable at this period. Group 2 instead showed a persistent remodelling of immature repair tissue. There was, however, a slight chondrogenic potential of the scaffold alone, suggested by some small peripheral areas of matrix positive for type II collagen, but the overall histological appearance of the scaffold-alone samples at 1 year postoperatively was similar to that of the fibrocartilaginous healing of the empty defects. The difference between Group 1 compared with the controls suggests a key role of the minced cartilage fragments in the HA-PRFM-fibrin glue scaffold as being a source of chondrocytes and conditioning factors during the repair process. The better healing observed in Group 1 , however, lacked the overall zonal organisation of hyaline cartilage, and showed some areas of incomplete repair, indicating that some improvement of the technique is still required. Nevertheless, histological results of the present study represent the basis for a suitable alternative to the new emerging one-stage methods. Additionally, we cannot exclude that further tissue remodelling may occur in a longer follow-up, although the final result of the experimental Group 1 is satisfactory for a functional repair tissue both histologically and biomechanically.
The biomechanical findings at 1 year showed a clear superiority of the Group 1 samples compared to the controls. A discrepancy can be noted by observing the greater difference between groups in the biomechanical tests compared to that measured by the histological scores. This apparent incongruence can be explained by the fact that the biomechanical analysis made by nanoindentation measured the superficial $100 \mu \mathrm{m}$ of the samples, whereas the histological scores employed in this study related to the whole sample field. Nanoindentation was chosen to provide the experimental model with more sensitivity and resolution, compared to other clinical hand-held macroindentation devices. In light of these results, Group 1 showed also the closest mechanical properties to healthy cartilage, while both control groups fared significantly worse. Nevertheless, there was a significant difference $(p<0.05)$ in the unloading curve for Hardness between Group 1 and healthy cartilage, confirming the substantially different properties of hyaline articular cartilage compared to that of the repair tissue derived from cartilage fragmentloaded scaffolds at the longest time point tested. Analysis of Young's modulus (E) in the loading curve does not contradict these previous observations, although its value is limited to just a slight depth of indentation, and it has to be considered as only being partially representative of the mechanical behaviour of the tissue. Compared to other studies (Franke et al., 2007), however, we observed overall greater values in $\mathrm{H}$ and $\mathrm{E}$ both for healthy cartilage and treated samples. This is most likely due to differences in hydrating conditions, sample preparation and storage of the specimens. This observation confirms that, in this model, biomechanical results should not be considered as absolute outcome measures for $\mathrm{H}$ and $\mathrm{E}$, but as relative indicators of the quality of the different repair tissues in the different experimental groups compared to a corresponding area of healthy cartilage.

As with other one-stage techniques, the method described has several hypothetical advantages for clinical applications. Intra-operative construct preparation is relatively simple, and it eliminates multiple surgeries and the high costs of cell culture-expansion. From a small biopsy, large defects could be treated by uniform tissue distribution into the scaffold. Natural adhesive properties of Hyaff-11, PRFM and fibrin glue do not need any sutures or staples for fixation, simplifying the surgical procedure. Due to the mouldable properties of this scaffold, constructs with minced fragments could be prepared as "paste-like" structures and thus be implanted arthroscopically for small lesions, similarly to the Hyalograft $\mathrm{C}$ technique (Kon et al., 2009).

Some observations should be noted with regard to the experimental study. Firstly, compared to a human setting, the situation described in the in vivo part can be considered a "worst case" scenario for the early postoperative period, as the goats were allowed to freely load on the operated limb. Although, in a quadruped such as the goat, it is likely that the load of the operated limb was partially reduced during the first postoperative period by the spontaneous transfer to the other three limbs, based on the pain. On the other hand, in human, patients are usually invited to reduce 
the load-bearing with crutches for the first 4 weeks in order to protect the implants and the early phase of the repair. However, this aspect did not hamper the stability of the implants in the treated animals, as no sign of detachment was seen from the histology of the euthanised animals in the earlier experimental time (1 month). Secondly, as previously mentioned, 3 animals died during the first 45 days of follow-up and were thus excluded. However, this did not affect the results of the study. Indeed, the study itself was designed in order to describe the entire repair process throughout all time points, allowing for appreciating the differences at 1, 3,6 and 12 months, especially for the experimental Group 1, and evaluating the final outcome of this new procedure at the longest time period. The number of animals and defects were sufficient to demonstrate a statistically relevant superiority of the experimental group at 1 year. Thirdly, we were not able to discriminate the cellular contribution to the repair process coming from the bone marrow, the synovial compartment and the cartilage surrounding the defects. In fact, due to the depth of the defects, cells from surrounding bone marrow could have migrated inside the scaffold, along with cells from synovial tissue and from the cartilage tissue at the perimeter of the defects, which could have adhered to the HA membrane. For this reason, different cell sources may have contributed to the final repair in all 3 groups. However, this confounding factor is common to all specimens and had therefore not jeopardised the differences between groups. A future study with a labelling technique could be employed to analyse this particular aspect.

\section{Conclusions}

These findings suggest that cartilage fragments loaded into a HA-PRFM-fibrin glue scaffold may facilitate the repair of osteochondral defects, and represent an effective alternative for a non-culture-based autologous one-stage repair technique. Both in vitro and in vivo, cartilage-like matrix was observed in the presence of chondral fragmentloaded scaffolds, suggesting that cartilage fragments represent a potential cell source for one-step procedures. Before clinical application, further studies are necessary in order to confirm the underlying mechanisms of this repair technique, both in a more mechanically challenging site, as in the medial femoral condyle, and in chronic lesions, which could respond differently to repair procedures and represent a more clinically relevant setting.

\section{Acknowledgements}

This work was supported by CRT (Cassa di Risparmio di Torino)-Alfieri project independent research fund. Authors are grateful to FAB (Fidia Advanced Biopolymers) for donation of Hyaff-11 membranes, Dr. Michele Petraroli for assisting with nanoindentation, and Dr Marco Forni for the invaluable help in image acquisition. We would also like to thank Radhika Srinivasan, $\mathrm{PhD}$, for careful editing of the manuscript. We wish to confirm that there are no known conflicts of interest associated with this publication and there has been no significant financial support for this work that could have influenced its outcome.

\section{References}

Ahern BJ, Parvizi J, Boston R, Schaer TP (2009) Preclinical animal models in single site cartilage defect testing: a systematic review. Osteoarthritis Cartilage 17: 705-713.

Bartlett W, Gooding CR, Carrington RWJ, Skinner JA, Briggs TWR, Bentley G (2005) Autologous chondrocyte implantation at the knee using a bilayer collagen membrane with bone graft. A preliminary report. J Bone Joint Surg Br 87: 330-332.

Bekkers JEJ, Inklaar M, Saris DBF (2009) Treatment selection in articular cartilage lesions of the knee: a systematic review. Am J Sports Med 37 Suppl 1: 148S-155S.

Bendinelli P, Matteucci E, Dogliotti G, Corsi MM, Banfi G, Maroni P, Desiderio MA (2010) Molecular basis of anti-inflammatory action of platelet-rich plasma on human chondrocytes: mechanisms of NF- $\kappa B$ inhibition via HGF. J Cell Physiol 225: 757-766.

Benthien JP, Behrens P (2011) The treatment of chondral and osteochondral defects of the knee with autologous matrix-induced chondrogenesis (AMIC): method description and recent developments. Knee Surg Sports Traumatol Arthrosc 19: 1316-1319.

Bobic V (1999) [Autologous osteo-chondral grafts in the management of articular cartilage lesions]. Orthopade 28: $19-25$.

Bonasia DE, Martin JA, Marmotti A, Amendola RL, Buckwalter JA, Rossi R, Blonna D, Adkisson HD 4th, Amendola A (2011) Cocultures of adult and juvenile chondrocytes compared with adult and juvenile chondral fragments: in vitro matrix production. Am J Sports Med 39: $2355-2361$.

Brittberg M, Tallheden T, Sjögren-Jansson B, Lindahl A, Peterson L (2001) Autologous chondrocytes used for articular cartilage repair: an update. Clin Orthop Relat Res 391 Suppl: S337-348.

Brittberg M, Winalski CS (2003) Evaluation of cartilage injuries and repair. J Bone Joint Surg Am 85 Suppl 2: 5869.

Buda R, Vannini F, Cavallo M, Grigolo B, Cenacchi A, Giannini S (2010) Osteochondral lesions of the knee: a new one-step repair technique with bone-marrow-derived cells. J Bone Joint Surg Am 92 Suppl 2: 2-11.

Carroll RJ, Arnoczky SP, Graham S, O’Connell SM (2005) Characterization of autologous growth factors in Cascade ${ }^{\circledR}$ platelet-rich fibrin matrix (PRFM). Musculoskeletal Transplant Foundation, Edison, NJ. Publication No. 128-XM 307C5.

Castillo TN, Pouliot MA, Kim HJ, Dragoo JL (2011) Comparison of growth factor and platelet concentration from commercial platelet-rich plasma separation systems. Am J Sports Med 39: 266-271.

Cavallo C, Desando G, Facchini A, Grigolo B (2010) Chondrocytes from patients with osteoarthritis express 
typical extracellular matrix molecules once grown onto a three-dimensional hyaluronan-based scaffold. J Biomed Mater Res A 93: 86-95.

Cole BJ, Farr J, Winalski CS, Hosea T, Richmond J, Mandelbaum B, De Deyne PG (2011) Outcomes after a single-stage procedure for cell-based cartilage repair: A prospective clinical safety trial with 2-year follow-up. Am J Sports Med 39: 1170-1179.

Custers RJH, Saris DBF, Dhert WJA, Verbout AJ, Van Rijen MHP, Mastbergen SC, Lafeber FPJG, Creemers LB (2009) Articular cartilage degeneration following the treatment of focal cartilage defects with ceramic metal implants and compared with microfracture. J Bone Joint Surg Am 91: 900-910.

Deponti D, Di Giancamillo A, Mangiavini L, Pozzi A, Fraschini G, Sosio C, Domeneghini C, Peretti GM (2012) Fibrin-based model for cartilage regeneration: tissue maturation from in vitro to in vivo. Tissue Eng Part A 18: 1109-1122.

De Windt TS, Concaro S, Lindahl A, Saris DBF, Brittberg M (2012) Strategies for patient profiling in articular cartilage repair of the knee: a prospective cohort of patients treated by one experienced cartilage surgeon. Knee Surg Sports Traumatol Arthrosc 20: 2225-2232.

Dhollander AAM, De Neve F, Almqvist KF, Verdonk R, Lambrecht S, Elewaut D, Verbruggen G, Verdonk PCM (2010) Autologous matrix-induced chondrogenesis combined with platelet-rich plasma gel: technical description and a five pilot patients report. Knee Surg Sports Traumatol Arthrosc 19: 536-542.

Franke O, Durst K, Maier V, Göken M, Birkholz T, Schneider H, Hennig F, Gelse K (2007) Mechanical properties of hyaline and repair cartilage studied by nanoindentation. Acta Biomater 3: 873-881.

Frisbie DD, Cross MW, McIlwraith CW (2006) A comparative study of articular cartilage thickness in the stifle of animal species used in human pre-clinical studies compared to articular cartilage thickness in the human knee. Vet Comp Orthop Traumatol 19: 142-146.

Frisbie DD, Lu Y, Kawcak CE, DiCarlo EF, Binette F, McIlwraith CW (2009) In vivo evaluation of autologous cartilage fragment-loaded scaffolds implanted into equine articular defects and compared with autologous chondrocyte implantation. Am J Sports Med 37 Suppl 1: 71S-80S.

Giannini S, Buda R, Vannini F, Cavallo M, Grigolo B (2009) One-step bone marrow-derived cell transplantation in talar osteochondral lesions. Clin Orthop Relat Res 467: 3307-3320.

Gomoll AH, Farr J, Gillogly SD, Kercher J, Minas T (2010) Surgical management of articular cartilage defects of the knee. J Bone Joint Surg Am 92: 2470-2490.

Gudas R, Gudaite A, Pocius A, Gudiene A, Cekanauskas E, Monastyreckiene E, Basevicius A (2012) Ten-year follow-up of a prospective, randomized clinical study of mosaic osteochondral autologous transplantation versus microfracture for the treatment of osteochondral defects in the knee joint of athletes. Am J Sports Med 40: 2499-2508.

Hall MP, Band PA, Meislin RJ, Jazrawi LM, Cardone DA (2009) Platelet-rich plasma: current concepts and application in sports medicine. J Am Acad Orthop Surg 17: 602-608.

Hunziker EB (1999a) Articular cartilage repair: are the intrinsic biological constraints undermining this process insuperable? Osteoarthritis Cartilage 7: 15-28.

Hunziker EB (1999b) Biologic repair of articular cartilage. Defect models in experimental animals and matrix requirements. Clin Orthop Relat Res 367 Suppl: S135-146.

Jackson DW, Lalor PA, Aberman HM, Simon TM (2001) Spontaneous repair of full-thickness defects of articular cartilage in a goat model. A preliminary study. $\mathrm{J}$ Bone Joint Surg Am 83: 53-64.

Kaul G, Cucchiarini M, Remberger K, Kohn D, Madry H (2012) Failed cartilage repair for early osteoarthritis defects: a biochemical, histological and immunohistochemical analysis of the repair tissue after treatment with marrow-stimulation techniques. Knee Surg Sports Traumatol Arthrosc 20: 2315-2324.

Knutsen G, Drogset JO, Engebretsen L, Grøntvedt T, Isaksen V, Ludvigsen TC, Roberts S, Solheim E, Strand T, Johansen O (2007) A randomized trial comparing autologous chondrocyte implantation with microfracture. Findings at five years. J Bone Joint Surg Am 89: 21052112.

Kon E, Gobbi A, Filardo G, Delcogliano M, Zaffagnini S, Marcacci M (2009) Arthroscopic second-generation autologous chondrocyte implantation compared with microfracture for chondral lesions of the knee: prospective nonrandomized study at 5 years. Am J Sports Med 37: 33 41.

Kon E, Mutini A, Arcangeli E, Delcogliano M, Filardo G, Nicoli Aldini N, Pressato D, Quarto R, Zaffagnini S, Marcacci M (2010a) Novel nanostructured scaffold for osteochondral regeneration: pilot study in horses. J Tissue Eng Regen Med 4: 300-308.

Kon E, Delcogliano M, Filardo G, Fini M, Giavaresi G, Francioli S, Martin I, Pressato D, Arcangeli E, Quarto R, Sandri M, Marcacci M (2010b) Orderly osteochondral regeneration in a sheep model using a novel nanocomposite multilayered biomaterial. J Orthop Res 28: 116-124.

Lewis PB, McCarty LP, Yao JQ, Williams JM, Kang R, Cole BJ (2009) Fixation of tissue-engineered human neocartilage constructs with human fibrin in a caprine model. J Knee Surg 22: 196-204.

Little CB, Smith MM, Cake MA, Read RA, Murphy MJ, Barry FP (2010) The OARSI histopathology initiative - recommendations for histological assessments of osteoarthritis in sheep and goats. Osteoarthritis Cartilage 18 Suppl 3: S80-92.

Liu Y, Shu XZ, Prestwich GD (2006) Osteochondral defect repair with autologous bone marrow-derived mesenchymal stem cells in an injectable, in situ, crosslinked synthetic extracellular matrix. Tissue Eng 12: 3405 3416.

Lu Y, Dhanaraj S, Wang Z, Bradley DM, Bowman SM, Cole BJ, Binette F (2006) Minced cartilage without cell culture serves as an effective intraoperative cell source for cartilage repair. J Orthop Res 24: 1261-1270. 
Madry H, Kaul G, Cucchiarini M, Stein U, Zurakowski D, Remberger K, Menger MD, Kohn D, Trippel SB (2005) Enhanced repair of articular cartilage defects in vivo by transplanted chondrocytes overexpressing insulin-like growth factor I (IGF-I). Gene Ther 12: 1171-1179.

Mahadev A, Mahara DP, Chang P, Mitra AK, Tay BK, Sim CS (2001) Autogenous osteochondral morselised grafts for full thickness osteochondral defects in the knee joints of pigs. Singapore Med J 42: 410-416.

Marmotti A, Bruzzone M, Bonasia DE, Castoldi F, Rossi R, Piras L, Maiello A, Realmuto C, Peretti GM (2012) One-step osteochondral repair with cartilage fragments in a composite scaffold. Knee Surg Sports Traumatol Arthrosc 20: 2590-2601.

Mithoefer K, Williams RJ 3rd, Warren RF, Potter HG, Spock CR, Jones EC, Wickiewicz TL, Marx RG (2005) The microfracture technique for the treatment of articular cartilage lesions in the knee. A prospective cohort study. J Bone Joint Surg Am 87: 1911-1920.

Peretti GM, Randolph MA, Villa MT, Buragas MS, Yaremchuk MJ (2000) Cell-based tissue-engineered allogeneic implant for cartilage repair. Tissue Eng 6: $567-$ 576.

Peretti GM, Randolph MA, Zaporojan V, Bonassar LJ, Xu JW, Fellers JC, Yaremchuk MJ (2001) A biomechanical analysis of an engineered cell-scaffold implant for cartilage repair. Ann Plast Surg 46: 533-537.

Peretti GM, Xu J-W, Bonassar LJ, Kirchhoff CH, Yaremchuk MJ, Randolph MA (2006) Review of injectable cartilage engineering using fibrin gel in mice and swine models. Tissue Eng 12: 1151-1168.

Peterson L, Vasiliadis HS, Brittberg M, Lindahl A (2010) Autologous chondrocyte implantation: a long-term follow-up. Am J Sports Med 38: 1117-1124.

Reindel ES, Ayroso AM, Chen AC, Chun DM, Schinagl RM, Sah RL (1995) Integrative repair of articular cartilage in vitro: adhesive strength of the interface region. J Orthop Res 13: 751-760.

Salzmann GM, Buchberger MS, Stoddart MJ, Grad S, Milz S, Niemyer P, Sudkamp NP, Imhoff AB, Alini M (2011) Varying regional topology within knee articular chondrocytes under simulated in vivo conditions. Tissue Eng Part A 17: 451-461.

Sánchez M, Anitua E, Azofra J, Andía I, Padilla S, Mujika I (2007) Comparison of surgically repaired Achilles tendon tears using platelet-rich fibrin matrices. Am J Sports Med 35: 245-251.

Sarrafian TL, Wang H, Hackett ES, Yao JQ, Shih M-S, Ramsay HL, Turner AS (2010) Comparison of Achilles tendon repair techniques in a sheep model using a crosslinked acellular porcine dermal patch and platelet-rich plasma fibrin matrix for augmentation. J Foot Ankle Surg 49: $128-134$.

Shapiro F, Koide S, Glimcher MJ (1993) Cell origin and differentiation in the repair of full-thickness defects of articular cartilage. J Bone Joint Surg Am 75: 532-553.

Simon B., Zatcoff A., Kong JJ., O’Connell S. (2009) Clinical and histological comparison of extraction socket healing following the use of autologous platelet-rich fibrin matrix (PRFM) to ridge preservation procedures employing demineralized freeze dried bone allograft material and membrane. Open Dent J 3: 92-99.

Stone KR, Walgenbach AW, Freyer A, Turek TJ, Speer DP (2006) Articular cartilage paste grafting to full-thickness articular cartilage knee joint lesions: a 2- to 12-year follow-up. Arthroscopy 22: 291-299.

Sundman EA, Cole BJ, Fortier LA (2011) Growth factor and catabolic cytokine concentrations are influenced by the cellular composition of platelet-rich plasma. Am J Sports Med 39: 2135-2140.

Ueblacker P, Wagner B, Vogt S, Salzmann G, Wexel G, Krüger A, Plank C, Brill T, Specht K, Hennig T, Schillinger $\mathrm{U}$, Imhoff AB, Martinek V, Gansbacher B (2007) In vivo analysis of retroviral gene transfer to chondrocytes within collagen scaffolds for the treatment of osteochondral defects. Biomaterials 28: 4480-4487.

Visser LC, Arnoczky SP, Caballero O, Egerbacher M (2010) Platelet-rich fibrin constructs elute higher concentrations of transforming growth factor- $\beta 1$ and increase tendon cell proliferation over time when compared to blood clots: a comparative in vitro analysis. Vet Surg 39: $811-817$.

\section{Discussion with Reviewer}

Reviewer II: Cells contributing to the in vivo repair could be recruited from the implanted scaffolds or the surrounding tissues or both - do you see ways of differentiating the roles of these cell populations?

Authors: This is an interesting question, focusing on one of the main observations of our in vivo study. Indeed, in the goat model the contribution to the repair may be derived both from the cells implanted by the scaffolds and from the surrounding tissues, such as the bone marrow, the synovial compartment and the cartilage surrounding the defects. In the literature, different studies have proposed a cell labelling technique to assess the location and the role of specific cell populations at the defect site, but this seems to be somehow impractical for our repair model, dealing with cartilage fragments embedded in a composite scaffold as a source of cells for the repair. On the other hand, a male source of fragments implanted in a female host could represent a possible solution to that issue, due to the possibility to detect cells carrying the $\mathrm{Y}$ gene sequence in the repair tissue by in situ hybridisation, as suggested by recent work of Dattena et al. (2009). Indeed, the use of scaffold with allogeneic chondral fragments transplanted to recipients of different gender may constitute an alternative to identify the position of the migrating chondrocytes in the repair tissue and to discriminate this particular cell population from the recipient cells of the surrounding tissue.

Reviewer II: The constructs consist of an array of components that due to their commercial source may have limited general and long-term availability. Can you speculate which components have the most favourable impact on healing and reversely which components could be left out or replaced with non-proprietary materials? 
Authors: The use of a composite scaffold has several advantages linked to the different properties of the components, and the choice of a commercially available source for the materials has, potentially, the clinical relevance of a "direct" application of the same tools. The Reviewer's observation is entirely appropriate because it is well known that commercial materials can be withdrawn for different reasons, spanning from commercial politics to emerging technologies that are offered in place of the previous components. We believe that two components are fundamental for the repair driven by cartilage fragments. The first is the fibrin glue. It allows the fragments to be bound together, stabilising the construct for the first phases of the repair, and facilitates the migration/outgrowth of chondrocytes toward the outer space through the fibrin net. This makes fibrin glue optimal for embedding cells for cartilage repair, also considering the possibility to modulate the formation of the "pores" simply by changing the concentration of the thrombin before the formation of the fibrin net. Besides, fibrin glue has also been proposed in the literature as a single scaffold for autologous chondrocyte implantation because of its peculiar properties (Bekkers et al., 2013; Wysocka A et al., 2010). However, the issue of the commercial availability of the fibrin glue could be simply solved in a potential clinical setting by preparing autologous fibrin glue from the blood of the patients or, as an alternative, by using allogeneic fibrinogen from voluntary donors stored in the local blood centre.

The second important component of the scaffold is certainly the HYAFF-11 membrane. The properties of a hyaluronic acid felt go beyond the simple action of "coverage" of a lesion, because the acid itself has chondrogenic properties and can positively influence the formation of cartilaginous tissue (Cavallo et al., 2010). The ease of application of this membrane makes this component very useful, being an "active" coverage of the osteochondral defect. Moreover, in different clinical papers, HYAFF-11 has already been used as a scaffold for one-stage cartilage repair together with bone marrow and platelet-rich plasma (Giannini et al., 2009; Buda et al., 2010). However, in the unlikely event HYAFF-11 being no longer available, another biological scaffold could be used as a substitute. The collagen I/III membranes used for the MACI technique (i.e. ChondroGide ${ }^{\circledR}$ ) may perform as well for the coverage of the defects, although its structure is more rigid and less permeable than that of the HYAFF felt. The bottom of the goat defects in our study was filled with a platelet-derived gel classified as "Platelet-richfibrin-matrix" (PRFM). This is the third component of the construct. It was chosen to fill the bottom of the defects for the malleability associated with a short-term delivery of growth factors. This type of platelets derivative is largely used in clinical settings. Some impact, in the very first phases of the healing process, may derive from the release of the growth factors stored in the platelets. However, the main action of this type of PRFM lies probably on the tridimensional structure of the fibrin network that is slowly resorbed and substituted by the host bone. If not available, it can be easily substituted for by more rigid components such as the demineralised bone matrix chips or, in case of superficial defects not involving major portions of the subchondral bone, it could be left out - provided that a sufficient filling is guaranteed by the other components of the constructs.

\section{Additional References}

Dattena M, Pilichi S, Rocca S, Mara L, Casu S, Masala G, Manunta L, Manunta A, Passino ES, Pool RR, Cappai P (2009) Sheep embryonic stem-like cells transplanted in full-thickness cartilage defects. J Tissue Eng Regen Med 3: 175-187.

Bekkers JE, Creemers LB, Tsuchida AI, van Rijen MH, Custers RJ, Dhert WJ, Saris DB (2013) One-stage focal cartilage defect treatment with bone marrow mononuclear cells and chondrocytes leads to better macroscopic cartilage regeneration compared to microfracture in goats. Osteoarthritis Cartilage 21: 950-956.

Wysocka A, Mann K, Bursig H, Dec J, Gaździk TS (2010) Chondrocyte suspension in fibrin glue. Cell Tissue Bank 11: 209-215. 